\title{
Impact Of Improved Building Thermal Efficiency On Residential Energy Demand
}

R. C. Adams

A. D. Rockwood

April 1983

Prepared for the U.S. Department of Energy under Contract DE-AC06-76RLO 1830

Pacific Northwest Laboratory

Operated for the U.S. Department of Energy by Battelle Memorial Institute 


\title{
DISCL.AIMER
}

This report was prepared as an account of work sponsored by an agency of the United States Government. Neither the United States Government nor any agency thereof, nor any of their employees, makes any warranty, express or implied, or assumes any legal liability or responsibility for the accuracy, completeness, or usefulness of any information, apparatus, product, or process disclosed, or represents that its use would not infringe privately owned rights, Reference herein to any specific commercial product, process, or service by trade name, trademark, manufacturer, or otherwise, does not necessarily constitute or imply its endorsement, recommendation, or favoring by the United States Government or any agency thereof. The views and opinions of authors expressed herein do not necessarily state or reflect those of the United States Government or any agency thereof.

\author{
PACIFIC NORTHWEST LABORATORY \\ operated by \\ BATTELLE \\ for the \\ UNITED STATES DEPARTMENT OF ENERGY \\ under Contract DE-AC06-76RLO 1830
}

\begin{tabular}{|c|c|}
\hline \multicolumn{2}{|c|}{$\begin{array}{c}\text { National Technical Information Service } \\
\text { United States Depaitment of Commerce } \\
5285 \text { Port Roval Road } \\
\text { Springfield, Virginia } 22151\end{array}$} \\
\hline \multicolumn{2}{|c|}{$\begin{array}{l}\text { NTIS Price Codes } \\
\text { Microfiche } A 01\end{array}$} \\
\hline \multicolumn{2}{|c|}{ Printed Copy } \\
\hline Pages: & $\begin{array}{l}\text { Price } \\
\text { Codes }\end{array}$ \\
\hline $001-025$ & $\mathrm{~A} 02$ \\
\hline $026-050$ & 103 \\
\hline $051-073$ & $\mathrm{NO4}$ \\
\hline 076.100 & A05 \\
\hline $107-125$ & A06 \\
\hline $126-150$ & A07 \\
\hline $151-175$ & 108 \\
\hline $176-200$ & $A 09$ \\
\hline $201-225$ & A010 \\
\hline $226 \cdot 250$ & $\mathrm{~A} 011$ \\
\hline $257-225$ & 1012 \\
\hline $276-300$ & $\mathrm{~A} 013$ \\
\hline
\end{tabular}


PNL -3733

UC-95d

IMPACT OF IMPROVED BUILDING

THERMAL EFFICIENCY ON

RESIDENTIAL ENERGY DEMAND

\author{
R. C. Adams \\ A. D. Rockwood
}

Apri1 1983

Prepared for the U.S. Department of Energy under Contract DE-AC06-76RLO 1830

Pacific Northwest Laboratory

Richland, Washington 99352 



\section{CONTENTS}

EXECUTIVE SUMMARY

vii

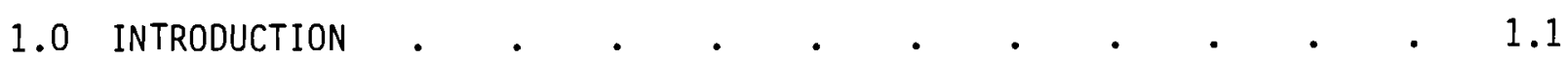

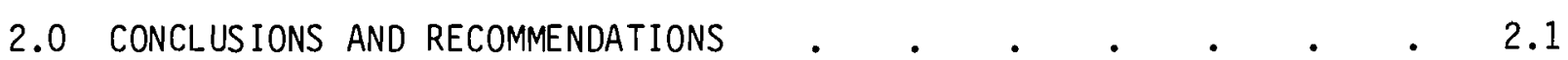

3.0 THE THEORETICAL RELATIONSHIP BETWEEN RESIDENTIAL THERMAL EFFICIENCY AND SPACE CONDITIONING ENERGY DEMAND $\quad . \quad \cdots \quad . \quad \cdot \quad 3.1$

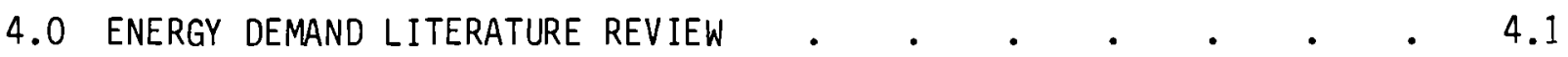

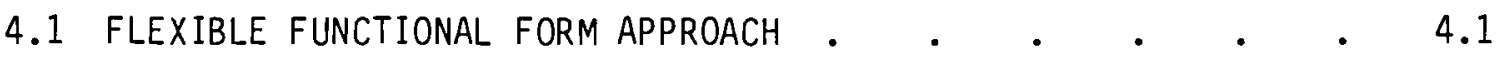

4.1.1 Trans log Utility Function Variation . . . . . 4.2

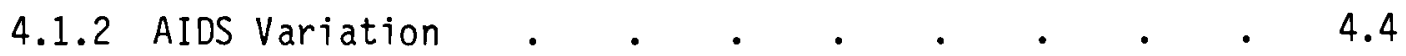

4.1.3 Other Flexible Functional Form Approaches . . . 4.5

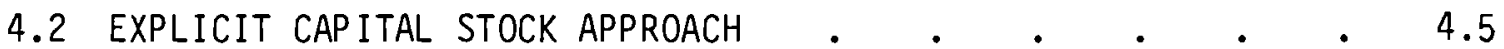

4.2.1 Appliance Aggregate Approach $\quad$. $\quad$. $\quad . \quad$. 4.6

4.2.2 Appliance Disaggregate Approach . . . . . . 4.8

4.2.3 Other Explicit Capital Stock Approaches . . . 4.8

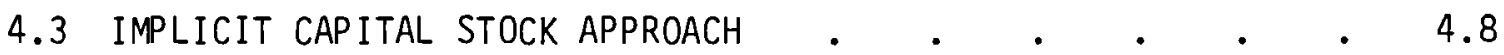

5.0 SPECIFICATION OF THE RESIDENTIAL ENERGY DEMAND MODEL $\quad$ • $\quad . \quad$ • 5.1

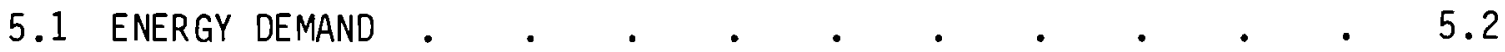

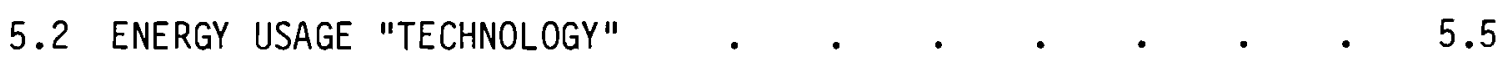

6.0 THE THERMAL EFFICIENCY INDEX AND OTHER VARIABLES

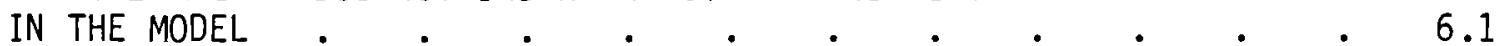

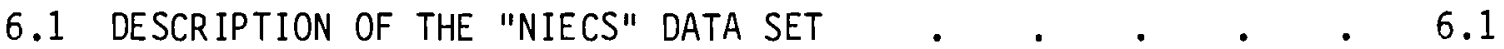

6.2 DERIVATION OF GAS AND ELECTRIC MARGINAL PRICES . $\quad$ • $\quad$ • 6.6

6.2.1 Theoretical Explanation of the Need

for Marginal Price . . . . . . . . . 6.6

6.2.2 Marginal Price Derivation . . . . . . 6.11

6.2.3 Marginal Price Estimation . . . . . . $\quad$. 6.12 
6.3 MEASURING THE EFFICIENCY OF THE STRUCTURE $\quad . \quad \ldots \quad$ • $\quad$ • 6.15

6.4 ELECTRIC AND GAS APPLIANCE INDEXES • • • • • • • • • 6.17

6.5 OBSERVATIONS DELETED FROM THE DATA SET • • • • • • 6.17

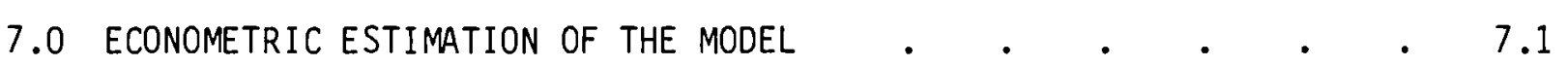

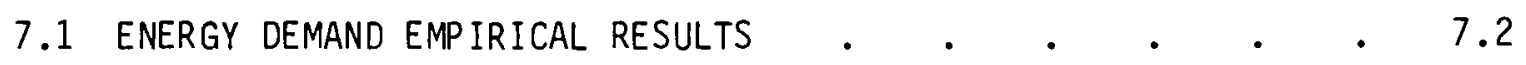

7.1 .1 Electric Air Conditioning . $\quad$. $\quad$ • . . 7.2

7.1 .2 Natural Gas Heat . . . . . . . . . 7.8

7.1 .3 Electric Heat $\quad$ • . . . . . . . 7.12

7.1.4 Limitations of the Energy Demand Results . . . 7.14

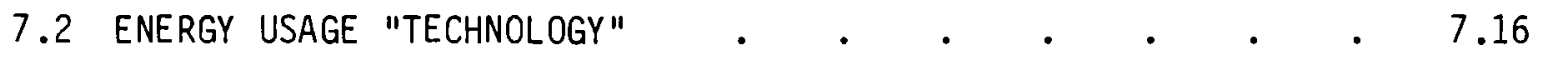

7.2.1 Primary Heating Fuel . . . . . . . . 7.16

7.2.2 The Level of Thermal Efficiency . • • • • 7.18

7.2.3 Choice of Air Conditioning Equipment . . . . 7.21

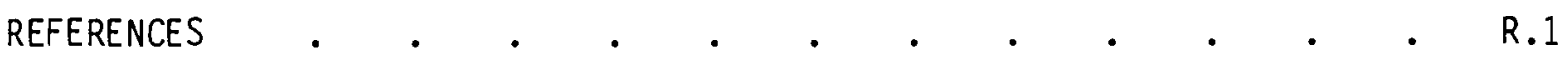

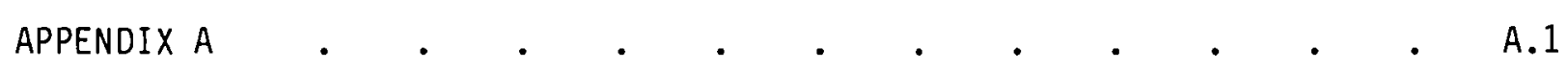




\section{FIGURES}

1 Climate Zones Defined by the AIA/RC with Census Regions and Divisions

2.1 Climate Zones Defined by the AIA/RC with Census Regions and Divisions

6.1 Changing Rate Structure and Energy Consumption Relationship . . . . . . . .

6.2 Changes in Energy Consumption as Related to Average and Marginal Price. . . . . . . . 6.10 


\section{TABLES}

1 Estimated Impact of a 20 Percent Increase in Shell Thermal

Efficiency on Space Conditioning Energy Demand . . . . . ix

2.1 Estimated Impact of a 20 Percent Increase in She 11 Thermal

Efficiency on Space Conditioning Energy Demand ..$\quad$. 2.2

2.2 Space Conditioning Fuel Price Elasticity Estimates . • • 2.2

6.1 Summary Statistics for Single Family Detached

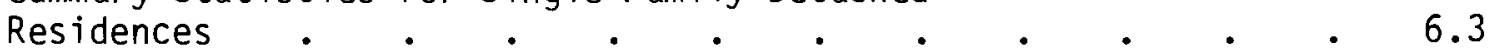

6.2 Summary Statistics for Single Family Attached

Residences

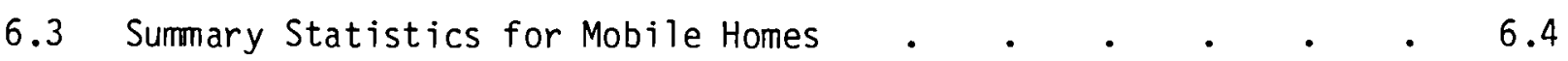

6.4 Summary Statistics for Residences in 2-4

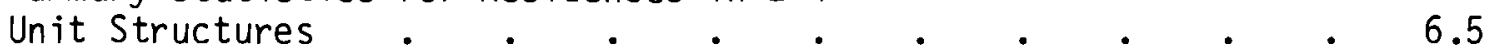

6.5 Summary Statistics for Residences in 5 or More
Unit Structures

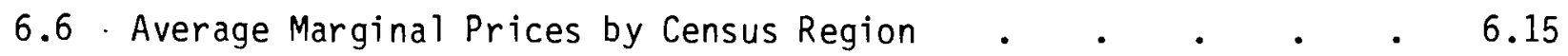

7.1 Electric Air Conditioning Empirical Results • 7.5

7.2 Air Conditioning Price and Efficiency Elasticity
Estimates

7.3 Estimated Impact of a $20 \%$ Increase in Shell Thermal
Efficiency on Air Conditioning Energy Demand . . . . $\quad$. 7.7

7.4 Gas Heating Empirical Results . . . . . . . . . 7.10

7.5 Gas Heat Price and Efficiency Elasticity Estimates . • • 7.11

7.6 Estimated Impact of a $20 \%$ Increase in She 11 Thermal

Efficiency on Gas Heat Energy Demand . $\quad . \quad$. $\quad . \quad$. 7.11

7.7 Electric Heat Empirical Results . . . . . . . . . 7.15

7.8 Fuel Choice LOGIT Regression Results - Gas Heat . • • • • 7.19

7.9 Thermal Efficiency Level Regression Results . • • • • • 7.19

7.10 Air Conditioning LOGIT Regression Results . • • • • • • 7.23

7.11 Central Air Conditioning LOGIT Regression Results $\quad$ • $\quad$ • $\quad$ - 7.23 


\section{EXECUTIVE SUMMARY}

This report describes research performed by the Pacific Northwest Laboratory for the Department of Energy, Office of Conservation and Renewable Energy. The principal objective of this residential energy demand study was to estimate the impact of improved building shell thermal efficiency on residential energy consumption. Acheiving this objective required an estimate of the thermal efficiency elasticity of demand (the percentage change in the quantity of energy used for space conditioning given a one percent change in shell thermal efficiency). Given an estimate of this elasticity, the percentage change in building shell thermal efficiency (caused by a conservation program or energy price increases) could be multiplied by the thermal efficiency elasticity estimate to generate a conservation impact estimate. A secondary objective of the study was to statistically analyze several residential energy demand related issues including primary heating fuel choice, thermal efficiency choice, and the decision to purchase central or room air conditioning equipment.

This report begins by exploring, in a theoretical framework, the impact of improved building shell thermal efficiency on residential energy demand. This analysis shows that the residential energy demand impact of improved thermal efficiency depends on two factors. The first factor is an engineering effect: conservation will reduce the amount of energy required to keep a residence at a given internal temperature level. The second factor is a behavioral effect: conservation will create an incentive for consumers to improve their internal comfort level (increase temperature in the winter and reduce temperature in the summer). Due to the increased amount of energy efficiency, the marginal cost of changing the internal temperature level in the residence to a more comfortable setting is lower. That is, the amount of additional fuel required to improve the internal temperature level is lower and therefore the cost is lower. As a result increases in thermal efficiency provide an incentive to improve the internal temperature level. The impact of thermal efficiency improvements on residential energy demand depends on the net impact of these two effects.

In addition, this analysis shows that the expected residential energy demand impact of improved thermal efficiency will depend upon the space conditioning fuel price elasticity of demand (the percentage change in the quantity 
of energy used to space condition given a one percent change in the price of fuel used to space condition). The thermal efficiency elasticity of demand is shown to equal one minus the space conditioning fuel price elasticity of energy dem and.

Following the theoretical analysis, the report reviews the important economic literature on estimating the price elasticity of residential energy demand. One approach emerges from this literature review which appears to be relevant to this study's objectives and suited to the available data. This is the disaggregated appliance stock approach which has the potential to produce estimates of the space conditioning fuel price elasticity of demand as well as thermal efficiency elasticity of demand estimates.

The third major section of this report presents the specification of the residential energy demand model. A variant of the disaggregated appliance stock model for residential energy use is developed and discussed in this report. Explanatory variables in the energy demand equation include natural gas and electricity prices, household income, house size (number of rooms), degree days, and the stock of appliances. The energy demand function is approximated by a variant of the transcendental logarithmic function. Through the interaction terms between prices and the appliance stocks, use specific price elasticities can be identified (e.g., space conditioning fuel price elasticity). The model also examines consumers' decisions relevant to heating fuel choice, the thermal efficiency of homes, and the purchasing of central or room air conditioners.

The fourth section of the report describes the data used within this study. The National Inter im Energy Consumption Survey (NIECS) data was used for all the empirical analysis in this project. The NIECS data base contains information on 4081 households in the U.S. A national random sampling technique was used to select the respondents. The data contains information on house characteristics and household characteristics. In addition information was available on billing period quantity and cost for electric and natural gas consumption, heating degree days and cooling degree days corresponding to the billing periods, and the length of the billing periods. 
The prefered specification for the equations within the residential energy consumption model required the development of several variables. This section of the report describes the methods used to derive four variables: 1) the marginal price (to the consumer) of electricity and natural gas, 2) a residential shell thermal efficiency index, 3) a non-space conditioning electric appliance index, and 4) a non-space conditioning natural gas appliance index. All these variables were derived using the NIECS data.

The final section of the report describes the empirical estimation of the residential energy demand model. Empirical results are described for equations that explain: 1) summer electricity consumption, 2) winter natural gas consumption, 3) winter electricity consumption, 4) residential primary heating fuel choice, 5) shell thermal efficiency choice, 6) the decision to air condition, and 7) the decision to use a central or room air conditioner. The empirical results show that the impact of shell thermal efficiency improvements on space conditioning energy consumption depends on the region specific variables such as heating degree days, cooling degree days, and the price of the fuel used to space condition.

Table 1 shows the upper and lower bound estimated impact of a 20 percent increase in shell thermal efficiency on space conditioning energy demand. The American Institute of Architects climate zones were used in the analys is (see Figure 1).

TABLE 1. Estimated Impact of a 20 Percent Increase in She 11 Thermal Efficiency on Space Conditioning Energy Demand

\begin{tabular}{|c|c|c|c|c|}
\hline \multirow[b]{2}{*}{$\begin{array}{l}\text { Climate } \\
\text { Zone }\end{array}$} & \multicolumn{2}{|c|}{$\begin{array}{l}\text { Electric Air } \\
\text { Conditioning } \\
\end{array}$} & \multicolumn{2}{|c|}{ Gas Heating } \\
\hline & $\begin{array}{l}\text { Upper } \\
\text { Bound } \\
\end{array}$ & $\begin{array}{l}\text { Lower } \\
\text { Bound }\end{array}$ & $\begin{array}{l}\text { Upper } \\
\text { Bound } \\
\end{array}$ & $\begin{array}{l}\text { Lower } \\
\text { Bound }\end{array}$ \\
\hline 1 & $-18.4 \%$ & $-11.6 \%$ & $-10.8 \%$ & $-5 \%$ \\
\hline 2 & $-18.6 \%$ & $-7 \%$ & $-10.8 \%$ & $-2.4 \%$ \\
\hline 3 & $-17 \%$ & $-5.4 \%$ & $-11 \%$ & $-7.4 \%$ \\
\hline 4 & $-14.2 \%$ & $0 \%$ & $-13.6 \%$ & $-3.2 \%$ \\
\hline 6 & $-9.2 \%$ & $0 \%$ & -- & -- \\
\hline 7 & $-9.8 \%$ & $0 \%$ & $-13 \%$ & $0 \%$ \\
\hline
\end{tabular}

-- Not available 
Twenty (20) percent is used here strictly for illustrative purposes. The ratio of estimated savings to improved thermal efficiency is constant by assumption. Thus, a 15 percent improvement in thermal efficiency would cause the percent energy savings estimate to decrease by one quarter relative to the 20 percent savings estimate.

Because of the method used to calculate the thermal efficiency index the authors hypothesize that the upper bound estimate is closer to the true impact of conservation than the lower bound estimate. For air conditioning the upper bound conservation impact estimate of the reduction in space conditioning fuel demand for a 20 percent increase in thermal efficiency ranges from -18.4 percent in the northern $c l$ imates to -9.2 percent in the southern climates. For natural gas heating the impact of the same 20 percent increase in thermal efficiency ranges from -10.8 percent in the northern $c 1$ imates to -13.6 percent in the southern climates. Only a national average impact was estimated for electric heating. The estimated upper bound change in electricity demand in electrically heated houses due to the same 20 percent increase in thermal efficiency is -13.6 percent. The lower bound estimate is -7.2 percent. In general, the results indicate that households in higher cooling degree day areas and the higher heating degree day areas will have a lower percentage reduction in the amount of fuel used to space condition. This, of course, does not imply that less energy will be saved in the higher degree day areas. The amount of energy saved depends on the percentage saved and the total quantity of energy used to space condition before the increase in thermal efficiency. 


\subsection{INTRODUCTION}

This research was performed by the Pacific Northwest Laboratory (PNL) for the Department of Energy (DOE), Office of Conservation and Renewable Energy. The principal objective of this research was to estimate the residential energy consumption impact of improved building shell thermal efficiency.

Our concern with the relationship between thermal efficiency and residential energy consumption has been motivated by the numerous energy conservation programs introduced in recent years, the most comprehensive of which has been the federally mandated Building Energy Performance Standards (BEPS) program. The objective of BEPS is to reduce the level of space conditioning energy used in new residential and commercial structures to minimum "practicable" levels.

BEPS identify minimum levels of shell thermal energy efficiency for newly constructed residential and commercial building. The criteria used to select the standards was a minimum life cycle cost criteria. The life cycle costing methodology used by $D O E$ assumed constant energy prices across regions in the U.S. Regional variations in the standards are due to regional climate differences. Two of the key assumptions used in life cycle costing analys is include: $1)$ an average real increase in electricity and gas prices of $1.54 \%$ and $2.81 \%$ per annum, respectively, and 2) a real rate of discount for the home dweller of 3\%. A complete discussion of the standard setting criteria can be found in Economic Analys is of Building Energy Performance Standards (DOE, 1980).

The Energy Conservation and Production Act (ECPA) of 1976 (Pub. L. 94-385) mandates the promulgation of BEPS. Section 302 of ECPA states that compliance with BEPS should be achieved through existing building codes and other construction control mechanisms or through a special approval process, but with a minimum of federal interference in state and local transactions. Section 305 of ECPA states that no federal financial assistance will be made available for the construction of any new commercial or residential building in any area of any state unlesS BEPS are adopted by state and local governments. However, both houses of Congress must approve this sanction before it becomes effective.

Obviously, one of the crucial elements when evaluating the efficiency of BEPS from a policy perspective is the impact of standards on residential energy consumption. The desire for information on this topic lead to this study. This 
report is divided into seven sections. Following the introduction and the conclusions sections, the economic theory relevant to the impact of improved residential energy efficiency on space conditioning energy demand is reviewed and related to BEPS. The fourth section of the report reviews the relevant energy demand literature. The fifth section presents the residential energy demand model specification. The sixth section of the report describes the data used to statistically estimate the residential energy demand model developed in the fifth section. The final section presents the empirical results and estimates of the impact of conservation on residential energy demand. 


\subsection{CONCLUS IONS AND RECOMMENDATIONS}

The following conclusions were derived from this study:

- Increases in shell thermal efficiency create an incentive to improve internal comfort level.

- The relationship between efficiency changes and space conditioning energy consumption depends on several region specific variables including heating degree days, cooling degree days and energy prices.

- The range of the conservation impact estimates for electric air conditioning and gas heating are shown in Table 2.1. A IA $\mathrm{climate}$ zones were used in the analysis (see Figure 1). Only an average electric heating conservation impact estimate was calculated. For a 20 percent increase in shell thermal efficiency in an electrically heated house the estimated upper bound impact on electric heating energy demand is -13.6 percent. The lower bound estimate is -7.2 percent. Due to the method used to generate a residential efficiency index, the authors hypothesize that the upper bound estimates (those estimates showing the greatest energy saving) are closer to the actual value than the lower bound estimates.

- The residential energy demand equations that were estimated produced estimates of space conditioning fuel price elasticities of demand for electric cooling, natural gas heating, and electric heating. Due to the way in which the equations were specified, the elasticity estimates are short run. Regional space conditioning fuel price elasticity estimates for electric air conditioning and gas heating are shown in Table 2.2. Only an average electric heating price elasticity was estimated, -0.32 .

- The conservation impact estimates are based on 1978/79 data. As fuel prices change the conservation impact of improved thermal efficiency will also change. The direction of change in the conservation impact cannot be determined a priori. 
TABLE 2.1. Estimated Impact of a 20 Percent Increase in Shell Thermal Efficiency on Space Conditioning Energy Demand

\begin{tabular}{|c|c|c|c|c|}
\hline \multirow[b]{2}{*}{$\begin{array}{l}\text { Climate } \\
\text { Zone }\end{array}$} & \multicolumn{2}{|c|}{$\begin{array}{l}\text { Electric Air } \\
\text { Conditioning } \\
\end{array}$} & \multicolumn{2}{|c|}{ Gas Heating } \\
\hline & $\begin{array}{l}\text { Upper } \\
\text { Bound }\end{array}$ & $\begin{array}{l}\text { Lower } \\
\text { Bound }\end{array}$ & $\begin{array}{l}\text { Upper } \\
\text { Bound }\end{array}$ & $\begin{array}{l}\text { Lower } \\
\text { Bound }\end{array}$ \\
\hline 1 & $-18.4 \%$ & $-11.6 \%$ & $-10.8 \%$ & $-5 \%$ \\
\hline 2 & $-18.6 \%$ & $-7 \%$ & $-10.8 \%$ & $-2.4 \%$ \\
\hline 3 & $-17 \%$ & $-5.4 \%$ & $-11 \%$ & $-7.4 \%$ \\
\hline 4 & $-14.2 \%$ & $0 \%$ & $-13.6 \%$ & $-3.2 \%$ \\
\hline 6 & $-9.2 \%$ & $0 \%$ & -- & - \\
\hline 7 & $-9.8 \%$ & $0 \%$ & $-13 \%$ & $0 \%$ \\
\hline
\end{tabular}

-- Not available

TABLE 2.2. Space Conditioning Fuel Price Elasticity Estimates

$\begin{array}{ccc}\begin{array}{c}\text { Climate } \\ \text { Zone }\end{array} & \begin{array}{c}\text { Electric } \\ \text { Air Conditioning }\end{array} & \begin{array}{c}\text { Gas } \\ \text { Heating }\end{array} \\ 1 & -0.08 & -0.46 \\ 2 & -0.07 & -0.46 \\ 3 & -0.15 & -0.45 \\ 4 & -0.29 & -0.32 \\ 6 & -0.54 & -- \\ 7 & -0.51 & -0.35\end{array}$

-- Not available

- The type of primary heating fuel and the level of thermal efficiency in a residential structure were estimated in a recursive model. First, the primary heating fuel was determined by the relative price of electricity and natural gas, the level of heating degree days, age of the structure, type of structure and whether it is owner occupied. Next, the efficiency level of the structure was determined by the prices of space conditioning fuels, heating degree days, age of the structure, type of structure and the type of primary heating fuel. 
CLIMATE ZONES

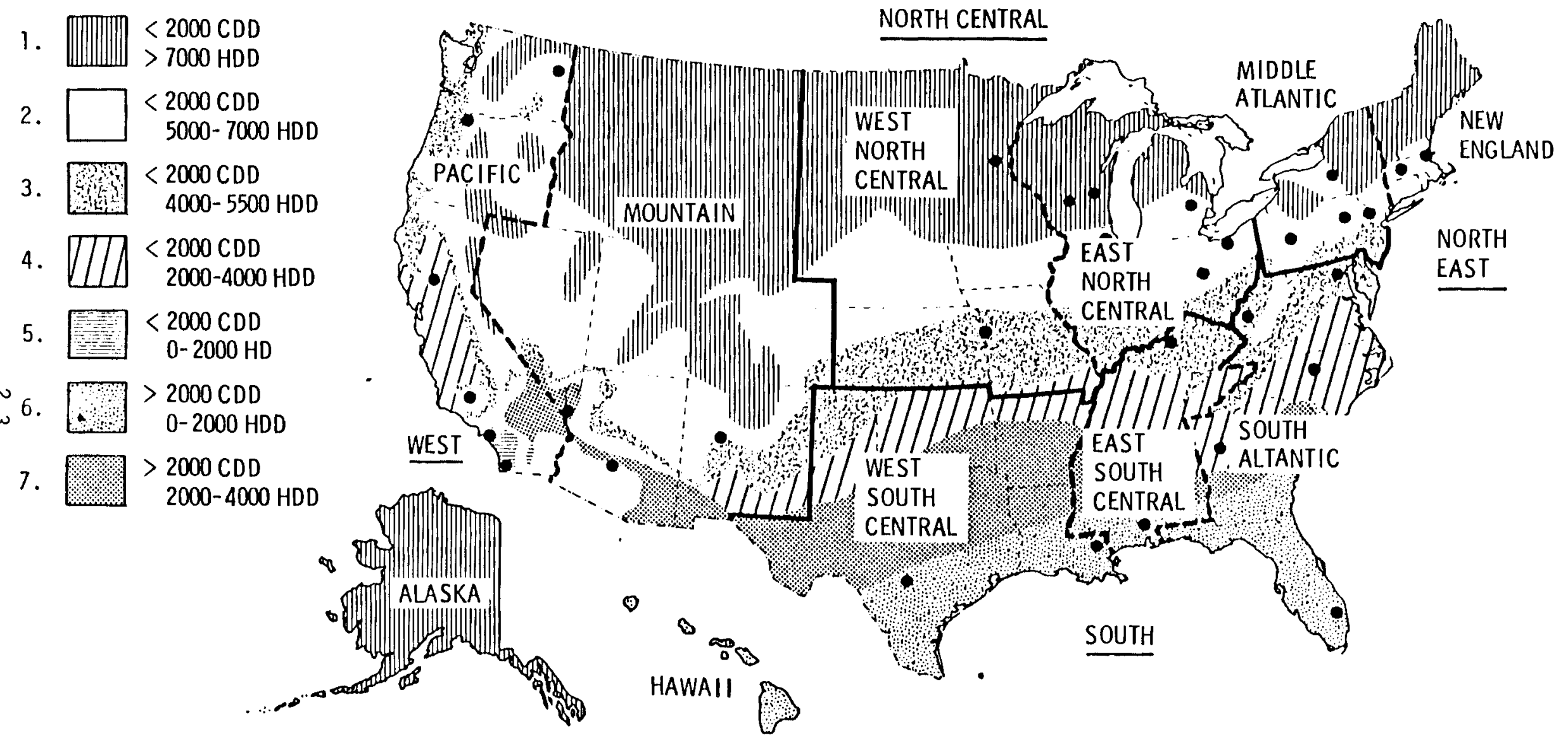

FIGURE 2.1. CLIMATE ZONES DEFINED BY THE AIA/RC WITH CENSUS REGIONS AND DIVISIONS 
- The stock of air conditioning equipment was analyzed in two steps: 1) whether to have any type air conditioning equipment; 2) if so, whether to acquire central air conditioning equipment. Both decisions relevant to air conditioning equipment are determined by the price of electricity, household income, age of the structure, type of structure, ownership of the residence, urban versus rural location and the $c l$ imate of the area (cooling degree days and hummidity). Electricity prices are a significant determinant of the choice of having any type of air conditioning equipment, but they are not a significant determinant in the choice between central and room air conditioners.

The following recommendations are made:

- The results of this study should be used when evaluating the energy savings of a proposed energy conservation program.

- The method used to develop the residential thermal efficiency index should be investigated for use in labeling the energy efficiency of residential structures.

- The conservation impact estimates derived in this study should be reestimated in the future to determine the stability of the estimates.

- The space conditioning fuel price elasticities estimated within this study should be used to update older elasticity estimates currently being used by DOE in various models.

- The thermal efficiency empirical equation should be used to determine how the market has been responding to fuel price increases. Market response estimates should be compared with full information optimal thermal efficiency decisions to estimate the value of an effective information program.

- The energy usage technology equations should be used, where possible, to improve current DOE models and methods. 


\subsection{THE THEORETICAL RELATIONSHIP BETWEEN RESIDENTIAL THERMAL EFFICIENCY AND SPACE CONDITIONING ENERGY DEMAND(a)}

The purpose of this section is to describe the theoretical relationship between residential energy demand and improved building shell thermal efficiency. This discussion will draw on some basic concepts in economic theory. Three basic concepts and relationships will be presented and discussed. Following this discussion these concepts will be used to demonstrate the relationship between thermal efficiency and residential energy demand.

First, the demand for residential energy is derived from the demand for residential services such as comfortable living space. Being a derived demand implies that consumers do not directly "consume" the energy they purchase. Instead, they use that energy to produce residential services such as cooking, water heating and comfortable living space. (The term "production of comfortable living space" will be used to describe space conditioning (heating and cooling) the interior of the residence.)

Second, in any production situation the productivity of the inputs used in the production process will affect the quantity of the input demanded. Consider a firm producing widgets; the productivity of labor in the production process will affect the quantity of labor demanded relative to other inputs in the production process. Further, labor productivity will affect the cost and the quantity of widgets produced by the firm. Households use inputs such as energy, a furnace and/or air conditioner, and the shell of the residence to produce a comfortable living environment. Thus, the efficiency of energy in producing a comfortable living environment will affect the quantity of energy demanded by the household for space conditioning purposes.

Consider the situation in which for some reason (e.g., BEPS) a house owner decides to improve the thermal efficiency of the shell of his residence. The effect of this change will be to reduce the quantity of energy required to keep the internal temperature level at a particular level. From the consumers'

(a) Our analys is of the relationship between residential energy efficiency and residential energy demand has drawn heavily from Warren-Boulton (1978). 
standpoint this change is equivalent to keeping the shell of the residence the same and increasing the thermal value of each unit of energy used in space conditioning. Thus, thermal efficiency improvements can be viewed as increasing the productivity of energy in the production of comfortable living space.

Third, residential energy demand is typically expressed in terms of consumer's willingness to pay for units of energy (measured in KWH's or MBTU), and their willing to pay for the other production inputs. However, because residential energy demand is a derived demand it is more accurate to specify that consumers are willing to pay for internal comfort (i.e., a comfortable living environment). As a result, the relevant price to the consumer is the price of internal comfort.

Given that consumers basic demand is for comfortable living space rather than units of energy, it would be helpful for the analysis to establish another unit to measure energy. To be consistent with the consumers' demand for space conditioning, the new unit of measure should reflect the productivity of energy in the space conditioning production process. This new measure of energy will be referred to an efficiency unit. The relationship between energy in efficiency units and energy in nominal units (e.g., KWH and MBTU) is defined as follows:

$$
E^{\prime}=e^{\theta} E
$$

where

$$
\begin{aligned}
E^{\prime}= & \text { the quantity of energy in efficiency units used for space } \\
& \text { conditioning } \\
\theta= & \text { an index measuring the thermal efficiency of the residence } \\
E= & \text { the quantity of energy in nominal units used for space } \\
& \text { conditioning. }
\end{aligned}
$$

The price of electricity can also be expressed in efficiency units. This price measures the cost of improving the internal temperature level in the residence. If the efficiency index is defined such that $E^{\prime} p^{\prime}=E p$, then it follows that:

$$
p^{\prime}=e^{-\theta} p
$$


where

$$
\begin{aligned}
& p^{\prime}=\text { price of energy in efficiency units } \\
& p=\text { price of energy in nomial units. }
\end{aligned}
$$

Given the nature of input demands, it follows that a demand function for residential energy use can be defined in terms of efficiency units and efficiency prices:

$$
E^{\prime}=f\left(p^{\prime}\right)
$$

From the definition of efficiency units and prices, the relationship between the thermal efficiency of residential structures and the residential demand for energy can be specified. As stated earlier, improving thermal efficiency can be viewed as augmenting the productivity of energy, i.e., factorsaving technological change. Factor saving technological change causes an increase in the efficiency parameter $(\theta)$.

Using Equations (3.1) and (3.2) the efficiency price of residential energy $\left(p^{\prime}\right)$ can be written as:

$$
p^{\prime}=p /\left(E^{\prime} / E\right)
$$

Equations (3.1), (3.2) and (3.3) can be used to solve for the energy input in quantity units as a function of nominal prices.

$$
\begin{aligned}
& E=e^{-\theta} E^{\prime} \\
& E=e^{-\theta} f\left(p^{\prime}\right) \\
& E=e^{-\theta} f\left(e^{-\theta} p\right)
\end{aligned}
$$

To determine the effect of an increase in factor productivity on the demand for the factor in quantity units, we differentiate Equation (3.7) with respect to $\theta$ : 


$$
\begin{aligned}
& \frac{\partial E}{\partial \theta}=-e^{-\theta} f\left(e^{-\theta} p\right)-e^{-\theta}\left[\partial f\left(e^{-\theta} p\right) / \partial\left(e^{-\theta} p\right)\right] e^{-\theta} p \\
& \frac{\partial E}{\partial \theta}=-e^{-\theta} E^{\prime}-e^{\theta}\left(\partial E^{\prime} / \partial p^{\prime}\right) p^{\prime} \\
& \frac{\partial E}{\partial \theta}=-e^{-\theta} E^{\prime}\left[1+\left(\partial E^{\prime} / \partial p^{\prime}\right)\left(p^{\prime} / E^{\prime}\right)\right] \\
& \frac{\partial E}{\partial \theta}=e^{-\theta} E^{\prime}\left(n^{\prime}-1\right)
\end{aligned}
$$

where $n^{\prime}=\frac{\partial E^{\prime}}{\partial n^{\prime}} \frac{p^{\prime}}{E^{\prime}}-$-the space conditioning fuel price elasticity of derived demand for êR'erğy in efficiency units of quantities and price. Alternatively, since $\eta^{\prime}=\eta$, where $\eta=\frac{\partial E}{\partial p} \frac{p}{E}$--the space conditioning fuel price elasticity of derived demand for energy in nominal units--we can express $\partial E / \partial \theta$ in quantity units as:

$$
\partial E / \partial \theta=E(n-1)
$$

From Equation (3.12) it follows that the effect of thermal efficiency improvements on the quantity of energy demanded depends on the space conditioning fuel price elasticity of demand for energy. If the demand for energy is inelastic $(n<1)$, then the quantity demand of energy will decrease as a result of the thermal efficiency improvement. If $n=1$, energy demand will be unchanged. If $\eta>1$, energy demand will increase as a result of the thermal efficiency improvement.

These results may be made clearer by considering the analogous relationship between automobile energy efficiency and automobile fuel use. Suppose that next year's automobiles are identical to current automobiles in all respects, except that they are $20 \%$ more fuel efficient. Owners of these new autos will experience a $20 \%$ reduction in the marginal cost associated with driving the vehicle each additional mile. The effect on the marginal cost per mile would be analogous to a decrease in the price of gasoline. Because the marginal cost per mile decreases, drivers would be expected to drive more miles as a result of the improvement in fuel efficiency. The only case in which this would not be true is if there was a completely inelastic demand for vehicle miles ( $i . e .$, the demand for miles driven is determined totally by factors other than the cost of fuel). The effect on fuel consumed as a result of the increase in efficiency would depend on the net effect of increased miles 
driven and decreased fuel consumption per mile. If the price elasticity of demand for gasoline is greater than one, the net effect on fuel consumption would be positive. If the price elasticity of demand for gasoline is less than one, the net effect on fuel consumption would be negative.

In the increased shell thermal efficiency case, the consumer's demand is for comfortable living space. Increased housing energy efficiency will cause a decrease in the marginal cost of keeping a house at a particular temperature. Thus, improved thermal efficiency will cause an incentive to improve the internal temperature setting. That is, as the marginal cost of conditioned space decreases (due to the improvement in energy efficiency) households will tend to improve their internal house temperature. This response will tend to increase fuel use, offsetting some or all of the efficiency gains. The only case in which temperature would not improve is if the demand for comfort was completely inelastic. The effect of improved thermal efficiency on residential energy demand for space conditioning depends upon the net effect of improved temperature level and decreased fuel consumption to keep the house at a particular temperature level.

This section has presented the theoretical relationship between improved shell thermal efficiency and residential energy demand. The next objective in the analysis was to develop a strategy that could be used to empirically estimate the space conditioning fuel price elasticity of demand controlling for thermal efficiency and the thermal efficiency elasticity of demand controlling for fuel price. From these parameter estimates, the energy consumption impact of improved thermal efficiency can be predicted. The first step was to survey the relevant empirical energy demand literature, which is discussed in the following section. 


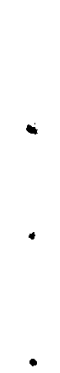




\subsection{ENERGY DEMAND LITERATURE REVIEW}

This report reviews relevant residential energy demand research described in the economics literature. This literature was used in formulating the theoretical model and empirical approach to be applied within this project. It contains the following structure. Three generic residential energy demand approaches and the major variations within each approach are described. After an explanation of the approach, some of the relevant research is listed. The three approaches will be referred to as the: 1) Flexible Functional Form approach, 2) Explicit Appliance Stock approach, and 3) Implicit Appliance Stock approach.

\subsection{FLEXIBLE FUNCTIONAL FORM APPROACH}

The Flexible Functional Form (FFF) approach is one method that can be used to derive a theoretical residential energy demand model. Several variations within the FFF approach are described below including the translog utility function (TUF) variation, and the Almost Ideal Demand System (AIDS) variation.

Economic theory states that individuals will consume that amount of goods that maximizes their total utility given their total expenditures are within their budget constraints. In most cases, the theoretical derivation of any demand equation is in some way based on this theory.

Using certain assumptions about the characteristics of consumer utility functions, specific functional forms have been derived for demand equations. Work by Stone (1954), Wold (1953), Houthakker (1960) and others was instrumental in the development of demand equations derived directly from utility functions. However, to derive the demand equations, restrictive assumptions had to be made in some cases regarding the consumer utility function. Two of the typical assumptions regarding utility function are additivity and homotheticity. Additivity implies that the marginal utility derived from the consumption of one good is independent of the consumption of all other goods. Homotheticity implies that the proportion of income spent on each good is independent of income (and utility) but may vary with prices. Demand equations derived from utility functions with less restrictive conditions would, in most cases, improve the empirical analysis. 
The FFF approach derives a demand system that is based on a minimum number of a priori restrictions on the consumer utility function. The empirically estimated FFF demand system does not require restrictive utility function assumptions such as additivity and homotheticity.

In general, the FFF approach involves the approximation of a utility function or a function directly related to the utility function. The approximating function is used to derive budget or share equations that can be empirically estimated; or the approximating function itself can sometimes be empirically estimated along with the functions derived from it. The empirically estimated parameters are then used to calculate expenditure elasticities and/or cross- and own-price demand elasticities for energy.

\subsubsection{Translog Utility Function Variation}

The direct utility function relates total utility to the quantity of commodities consumed. The direct utility function, U, can be represented as,

$$
\ln U=\ln U\left(x_{1}, x_{2}, \ldots, x_{n}\right)
$$

where $x_{i}$ represents the quantity of commodity $i$ consumed per unit of time. In addition, the negative of this logarithmic form of $U$ can be approximated by a function quadratic in the logarithms of the quantities consumed (translog function ),

$$
-\ln U=\alpha_{0}+\sum_{i} \alpha_{i} \ln x_{i}+1 / 2 \sum_{i} \sum_{j} \beta_{i j} \ln x_{i} \ln x_{j}
$$

This approximation allows the utility function to have a flexible functional form with minimum a priori restrictions.

Using Equations (4.1), (4.2) and basic principles of economic theory, budget share equations can be derived (Christensen et al. 1975),

$$
\frac{P_{j} X_{j}}{M}=\frac{\alpha_{j}+\sum_{i} \beta_{j i} \ln x_{i}}{\alpha_{m}+\sum_{i} B_{m i} \ln x_{i}}
$$


where $P_{j}$ is the price of commodity $j, M$ is the total expenditure on al 1 commodities and the $\alpha^{\prime} s$ and $\beta^{\prime} s$ are parameters to be estimated.

An indirect utility function can also be used to derive budget share equations. An indirect utility function, $V$, relates the maximum utility level attainable to given prices and total expenditure,

$$
\ln V=\ln V\left(P_{1} / M, \ldots, P_{n} / M\right)
$$

The negative of this logarithmic form of $V$ can be represented by a function quadratic in the logarithms of prices and expenditure (translog function),

$$
-\ln V=\alpha_{0}+\sum_{i} \alpha_{i} \ln \left(P_{i} / M\right)+1 / 2 \sum_{i} \sum_{j} \beta_{i j} \ln \left(P_{i} / M\right) \ln \left(P_{j} / M\right)
$$

Using Equations (4.4) and (4.5) (Christensen et a1. 1975),

$$
\frac{P_{j} x_{j}}{M} \frac{\alpha_{i}+\sum_{i} \beta_{j i} \ln \left(P_{i} / M\right)}{\alpha_{m}+\sum_{i} \beta_{m i} \ln \left(P_{i} / M\right)}
$$

Using several equation constraints that are derived directly from economic theory, the parameters of Equation (4.3) or (4.6) can be statistically estimated. The empirical results can then be used to calculate expenditure elasticities, own-price elasticities and cross-price elasticities (Christensen and Maser 1975). The results can also be used to test for the presence of certain utility function characteristics such as homotheticity and additivity (Christensen et a1. 1975).

Utility function constraints such as homotheticity and additivity can, of course, be imposed on the utility function before the budget share equations are derived. The introduction of utility function constraints will alter the budget share equations, and some utility function constraints will make the budget share equations linear, which will allow for easier statistical estimation. The relationship between some utility function constraints and the budget equations is detailed in Christensen and Maser (1975). 
The translog function has been used to approximate the utility function and derive budget share equations in several residential energy demand studies including Pindyck (1980) and Miedema et al. (1978).

\subsubsection{AIDS Variation}

The Almost I deal Demand System (AIDS) uses a cost or expenditure function that defines the minimum expenditure necessary to attain a specific utility level at a given set of commodity prices (Deaton and Muellbauer, 1980). The expenditure function, $E$, can be represented by,

$$
E=(1-u)[\ln (a(p))]+u[\ln (b(p))]
$$

where $u$ is the utility level, $a(p)$ is the cost of subsistance (minimum commodities necessary for survival) and $b(p)$ is the cost of bliss (maximum attainable level of utility). The cost of subsistance and bliss are then approximated with the following functional forms,

$$
\begin{aligned}
& \ln (a(p))=a_{0}+\sum_{k} \alpha_{k} \ln P_{k}+1 / 2 \sum_{k} \sum_{j} \gamma_{k j}^{k} \ln P_{k} \ln P_{j} \\
& \ln (b(p))=\ln (a(p))+\beta_{0} \prod_{k} P_{k}^{\beta_{k}}
\end{aligned}
$$

where $P_{k}$ is the price of commodity $k$. Using Equations (4.8) and (4.9), the following budget share equations can be derived,

$$
\begin{aligned}
\frac{P_{i} X_{i}}{\sum_{i} P_{i} X_{i}} & =\left(\alpha_{i}-\beta_{i} \alpha_{0}\right)+\sum_{j} \gamma_{i j} \ln P_{j}+\beta_{i}\left[\ln C-\sum_{k} \alpha_{k} \ln P_{k}\right. \\
& \left.-1 / 2 \sum_{k} \sum_{j} \gamma_{k j} \ln P_{k} \ln P_{j}\right]
\end{aligned}
$$

where $C$ is total consumer expenditure.

Estimation of the budget share equations shown in Equation (4.10) will allow calculation of own- and cross-price elasticities for energy. (Note that $u$ is not present in Equation (4.10) and, therefore, "money income" compensated 
demand elasticities can be derived.) From an empirical standpoint a basic advantage of this variation relative to the TUF variation is that a share equation is derived that is linear in the parameters.

This approach has not been used to date to estimate residential energy demand. However, research (not rel ated to this project) is beginning at PNL that will use this approach for estimating energy demand equations.

\subsubsection{Other Flex ib le Functional Form Approaches}

The translog function has also been used to approximate housing service cost functions from which input demand equations (e.g., energy) can be derived. A problem with this approach is that the demand equations derived using this approach are, in some cases, "income compens ated" demand equations. The housing services production function must be assumed to have certain characteristics including homotheticity before "money compensated" demand curves are derived and the corresponding price elasticitites can be derived (see Glandon and Pollakowski 1978).

Hausman et al. (1979), have used the indirect utility function in a somewhat different way to derive own and cross-price elasticities for energy. Using Roy's Identity and the indirect utility function, an equation relating relative energy prices and the ratio of energy consumption in period $n$ to energy consumption in the base period is derived. The equation is approximated using a Taylor expansion. The Taylor expansion is then statistically estimated and the empirical results are used to derive the energy price elasticities.

One final note needs to be included on the flexible functional form approach. As is true with other approaches, the elasticities derived depend on the type of data used in the analysis. Most of the work has used time series annual data; thus, the derived elasticities are basically short-run.

\subsection{EXPLICIT CAPITAL STOCK APPROACH}

The demand for energy is a derived demand. That is, consumers do not demand energy in and of itself, but rather services from appliances such as space conditioners and dishwashers that use energy. Because many appliances are durable goods, there is a distinction between short-run and long-run demand for energy. By definition, the short-run demand for energy is related only to 
the utilization of existing appliances. In the long run the appliance stock is variable; thus, the demand for energy is related to the choice of appliances as well as to the utilization of the appliances. As a result a proper model of energy demand should explicitly consider the distinction between short run and long run and therefore the model should consider endogenously the stock of household appliances.

Several residential energy demand studies have endogenously considered the stock of existing appliances. These studies have been grouped into the category of explicit capital stock approach. Within this approach there are several variations including the appliance aggregate approach and the appliance disaggregate approach.

\subsubsection{Appliance Aggregate Approach}

In general, this variation starts with the following identity,

$$
q=(u)(s)
$$

where $q$ is the quantity of energy consumed, $u$ is the utilization rate of the appliance stock, and $s$ is the potential number of watts the appliance stock can draw. The utilization rate is specified as a function of the price of electricity, $\left(P_{e}\right)$, income, $(Y)$, and other relevant variables, $(Z)$. Thus, we can rewrite Equation (4.11) as,

$$
q=\left(u\left(P_{e}, Y, Z\right)\right)(s)
$$

The next step is to assume some functional form for the utilization relationship such as linear, log linear or log-log. If the linear form was picked then Equation (4.12) could be represented as,

$$
q=\alpha_{0} s+\alpha_{1} p_{e} s+\alpha_{2} Y_{s}+\alpha_{3} Z s
$$

or

$$
q / s=\alpha_{0}+\alpha_{1} p_{e}+\alpha_{2} \gamma+\alpha_{3} z
$$


Often $s$ is not empirically known; thus, a surrogate is required to statisticallly estimate either Equation (4.13) or (4.14). Some data on appliance stock is available, as is some information on average utilization rates within states and the nation. Thus, one variation is to define $s(t)$ (i.e., $s$ in time t) as follows,

$$
s(t)=\sum_{i} w_{i} s_{i}(t)
$$

where $s_{i}$ represents the saturation rate of the $i^{\text {th }}$ appliance and $w_{i}$ is a weighting factor defined as,

$$
w_{i}=u_{i} / \sum_{i} u_{i}
$$

and $u_{i}$ is the utilization rate of the $i^{\text {th }}$ appliance. Equations (4.15) and (4.16) will allow estimation of either Equation (4.13) or (4.14). The own- and cross-price short-run elasticities could then be derived from the empirical results.

In the long run the stock of appliances is variable. Thus, the residential demand for energy is directly related to the consumption of appliances. To derive long-run elasticities, an appliance stock equation is specified that is similar to the following:

$$
s=\alpha_{0}+\alpha_{1} y+\alpha_{2} P_{e}+\alpha_{3}(r+d) P_{c s}+\alpha_{4} Z
$$

where $r$ is the market rate of interest, $d$ denotes the rate of depreciation of the capital stock, and $P_{c s}$ denotes the price per watt of additions to the capital stock. Estimation of Equation (4.17), information on the long-run utilization of the appliance stock and Equation (4.11) will allow calculation of the own- and cross-price elasticities of demand. Note that Equation (4.17) is actualiy a group of equations, one for each appliance. The appliance aggregate approach has been used by several researchers including Taylor (1977). 


\subsubsection{Appliance Disaggregate Approach}

A second variation of this approach involves disaggregation of the $s$ variable by appliance categories. The stock, $s$, is typically subdivided into appliance grouping with relatively homogeneous utilization rates such as air conditioner, heater, refrigerator, water heater and all others. Because of the assumed homogene ity of utilization rates, s simply becomes the saturation rate of the appliance category and the estimating equation becomes,

$$
\begin{aligned}
q= & b_{01} s^{(1)}+b_{11} P_{e^{s}}(1)+b_{21} Y_{s}^{(1)}+b_{31} Z s(1)+\ldots \\
& +b_{0 m} s^{(m)}+b_{1 m} P_{e^{s}}(m)+b_{2 m} Y_{s}^{(m)}+b_{3 m} Z s^{(m)}
\end{aligned}
$$

where $s^{(i)}$ is the saturation rate of the $i^{\text {th }}$ appliance group.

Empirical estimation of Equation (4.18) will allow estimation of the shortrun own- and cross-price elasticities of demand. This type of variation has been used by several researchers including Parti and Parti (1979) and Werth (1978). Estimation of the long-run elasticities within this variation is the same as that described for the appliance aggregate variation.

\subsubsection{Other Explicit Capital Stock Approaches}

Some researchers have simply specified the quantity of energy consumed as a function of the appliance stock in an ad hoc manner. Using this approach the researcher generally states that the arguments of the residential energy demand function are known (price, income, degree days, etc.) and then picks a functional form to estimate the equation. Elasticity estimates derived from this type of approach generally can be either short run or long run depending on the nature of the data used. Researchers that have used this type of approach include Chern and Lin (1978).

\subsection{IMPLICIT CAPITAL STOCK APPROACH}

An alternative approach to the residential energy demand model does not explicitly consider the appliance stock of residences. This approach is referred to as the flow adjustment approach. 
Changes in the consumption of energy, $\hat{q}(t)$, are assumed to be proportional to the discrepancy between the desired flow of energy $q^{\star}(t)$ and the actual flow $q(t)$,

$$
\hat{q}(t)=\gamma[q \star(t)-q(t)]
$$

where a functional form such as the following is specified for $q^{\star}(t)$,

$$
q^{\star}(t)=\alpha_{0}+\alpha_{1} Y(t)+\alpha_{2} p_{e}(t)+\alpha_{3} Z(t)
$$

where $Y, P_{e}$, and $Z$ are defined as before.

The equation to be empirically estimated can be derived from Equations (4.19) and (4.20),

$$
\begin{aligned}
\hat{q}(t)= & A_{0}+A_{1} q(t-1)+A_{2}(Y(t)+Y(t-1))+A_{3}\left(P_{e}(t)\right. \\
& \left.+P_{e}(t-1)\right)+A_{4}(Z(t)+Z(t-1))+e_{t}
\end{aligned}
$$

Estimation of Equation (4.21) will al low the calculation of the short-and longrun price elasticities of demand for residential energy. This type of approach has been use by Taylor (1977), Houthakker, Verleger and Sheehan (1974), and Parhizgari and Davis (1978). 


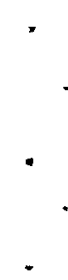




\subsection{SPECIFICATION OF THE RESIDENTIAL ENERGY DEMAND MODEL}

One of the principal objectives of this research was to derive estimates of the space conditioning fuel price elasticity of demand. An energy demand equation is developed in this section to facilitate the calculation of separate air conditioning, space heating and other appliance energy price elasticities of demand. A number of directly related issues, such as the choice of primary heating fuel, the economic determinants of thermal residential efficiency levels and the stock of energy using appliances are also examined.

As noted in Section 4, one of the advantages of the disaggregated appliance stock approach to energy demand modeling is that it directly yields estimates of price elasticities for individual energy uses. Because of the importance of this advantage relative to the objectives of the research, a variant of the disaggregated stock approach was used in this analysis. The information provided on end use specific price elasticities facilitated the identification of the relationship between shell thermal efficiency and residential energy demand for space conditioning.

The methodology used in this study differs from previous studies that have used the disaggregated stock approach. From a theoretical perspective the most important change was the inclusion of a thermal efficiency index in the model. This eliminated a potential bias in the space conditioning fuel price elasticity. The second major difference was the construction and use of marginal (to the consumer) natural gas and electricity prices. Previous studies using household data utilized average fuel prices. In addition, by using a variant of transcendental logarithmic function the estimating equation was more "flexible" than those used in other studies.

The model of residential energy demand is divided into two parts. The first part of the model determines the quantity of residential energy demanded using the framework of a household production function. The second determines the "technology" of energy usage in the household. By the "technology" of usage, we are referring to the thermal efficiency of the residential structure and the stock of energy using appliances owned by the household. Individual equations of the model are discussed in the following paragraphs. 


\subsection{ENERGY DEMAND}

The consumer is assumed to derive satisfaction from two basic commodities: residential services $(R)$ and a composite commodity $\left(Z_{c}\right)$ that represents all other goods and services. Residential services can be subdivided into space conditioning $\left(R_{1}\right)$ and other $\left(R_{2}\right)$. Energy is an input to the household's production of both residential services along with the stock of appliances and the thermal efficiency of the residential structure.

Households receive utility from these commodities according to the following utility function:

$$
U\left(R_{1}, R_{2} ; Z_{c}\right)
$$

We further assume that consumer preferences are homothetic and separable between the two residential services $\left(R_{1}\right.$ and $\left.R_{2}\right)$ and the composite commodity $\left(Z_{c}\right)$. Households produce residential services corresponding to the implicit production function $F\left(Q,, S\right.$; $\left.R_{1}, R_{2}\right)$, where $Q$ is the quantity of energy, is the thermal efficiency of the structure and $S$ is the stock of energy appliances. Although efficiency is the composite of several inputs and the building technology, we treat it simply as an input to the production of residential services. Consumer behavior is determined by the desire to maximize the utility function, subject to the production function and budget constraints.

The solution of the households' utility maximization problems can be considered in two parts: cost minimization for the production of residential services and utility maximization over the basic commodities. (a) As we have assumed that the utility derived from residential services is separable from the consumption of the composite commodity, and the production of the composite commodity is independent of the production of residential services, we are concerned throughout the balance of this paper only with residential services.

Part 1: Households are assumed to determine the minimum cost producing any given bundle of $R_{1}$ and $R_{2}$. Where $C$ is the cost, minimize

(a) See John Muellbauer (1974) for a full discussion of the problem. 


$$
C=P_{q} Q+P_{\theta} \theta+P_{s} S
$$

subject to

$$
F\left(Q, \theta, S ; R_{1}, R_{2}\right)
$$

The letter $P$ is used as the notation for the market price of the input designated by the subscript on $P$. The solution to this constrainted minimization defines the joint cost function:

$$
C=C\left(P_{q}, P_{\theta}, P_{s} ; R_{1}, R_{2}\right)
$$

Part 2: Households then are able to maximize their utility function subject to the cost functions

$$
\begin{aligned}
\operatorname{Max} L= & U\left(u\left(R_{1}, R_{2}\right), u\left(Z_{c}\right)\right)+\left(Y-C_{r}\left(P_{q}, P_{\theta}, P_{s}, R_{1}, R_{2}\right)\right. \\
& \left.-C_{z}\left(P_{c} ; Z_{c}\right)\right)
\end{aligned}
$$

From the maximization of the utility function, we can determine the demand for energy, appliances and efficiency as a function of the relative price of fuel efficiency and appliances household income.

$$
\begin{aligned}
& Q=Q\left(P_{q}, P_{S}, P_{\theta}, Y\right) \\
& S=S\left(P_{q}, P_{S}, P_{\theta}, Y\right) \\
& \theta=\theta\left(P_{q}, P_{S}, P_{\theta}, Y\right)
\end{aligned}
$$

The stock of appliances is a durable good, the structure's efficiency is embodied in durable goods, and therefore each of these inputs are determined by past prices and household incomes. Thus at any point in time, $\theta$ and $S$ are fixed and for our immediate purposes and can be considered exogenous to the consumer choice problem. This will add two additional constraints to maximization problem: $S=\bar{S}$ and $\theta=\bar{\theta}$. The result of these constraints is that the prices of appliances and efficiency will not enter the energy demand function. 
However, energy demand will depend on the predetermined levels of these inputs ( $\bar{S}$ and $\bar{\theta}$ ), as is shown in Equation 5.8. Because the stock of appliance and the thermal efficiency of stock are held constant the estimated price elasticity of fuel demand from this equation will be a short-run elasticity. Note also that the model is recursive such the energy demand equation can be estimated separately from the other equations.

$$
Q=Q\left(P_{q}, Y, \bar{S}, \bar{\theta}\right)
$$

The precise functional form of Equation 5.8 is uncertain. Therefore, for empirical estimation, we shall use a variant of a transcendental logarithmic (trans-log) function which provides a general approximation to any functional form. To further identify the demand schedule for residential energy usage, additional variables are included in the specification. These include degree days variables for both summer and winter and the size of the residence.

The general form of the trans-log equation is given below in Equation 5.9. A priori we expect significant interaction affects among prices, thermal efficiency, and climatic variables (these variables are represented by the vector $X)$. At different levels the consumer may have different substitution possiblities or simply come to choose different trade-offs. Therefore, we specify the trans-log function with second order terms for these variables. These interaction terms will allow the fuel price elasticity estimates to vary by the climate area and price level. An interaction effect is also expected between price and the stock of other energy using appliances. This will permit the independent estimation of the space conditioning price elasticity. The interaction term between price and other appliance will control for variations in energy consumption due to the demand for water heating, cooking, lighting, etc. The interaction term between price and degree days will capture the effects of price on spacing demands only. Thus, separated fuel price elasticities can be computed for fuel used for space conditioning. Only first order terms are included for income and structure size (These variables are represented by the vector $W$ ). In Equation 5.9, e presents a stochastic error term. 


$$
\ln Q=\ln \alpha_{0}+\sum \alpha_{i} \ln x_{i}+\sum \sum \beta_{i j} \ln x_{i} \ln x_{j}+\sum \gamma_{k} W_{k}+e
$$

Equation 5.9 will be estimated separately for several subsegments of the sample of households based upon the fuel used to space conditioning equipment and season of the year. The stratifications are: winter-electric heating equipment, winter-natural gas heating equipment and summer-electric air conditioning quipment. These divisions will permit the space conditioning fuel price elasticities to vary with the types of technology embodied in the fuel type chosen.

\subsection{ENERGY USAGE "TECHNOLOGY"}

The second segment of the energy demand model describes the household's acquisition of energy using appliances and does not assume that characteristics of the stock are fixed. This includes consumers' choices for heating fuel and thermal efficiency, as well as the decision to purchase central or room air conditioning equipment.

Consumers choose their heating fuel type based upon the relative prices of the fuels and their heating requirements. Equation 5.10 specifies residential heating fuel choice as a function of the price of electricity $\left(P_{e}\right)$, the price of natural gas $\left(P_{g}\right)$, heating degree days (HDD), structure type (ST), a dummy variable for the period when the structure was built (PD), and a dummy variable for owner occupied housing (OWN). The estimation of the parameters of Equation 5.10 poses a slightly different problem from the familiar multiple regression estimators. The dependent variable is dichotomous--the household either chooses electric heat or it does not. Thus the dependent variable must be transformed. We utilitize a 'LOGIT' transformation, specifying the dependent variable as the log of the odds of having electric heat. The odds are defined as the probability of having natural gas heat divided by the probability of not having natural gas heat $\left(\ln \left(F_{g} / F_{e}\right)\right)$.

$$
\ln \left(F_{g} / F_{e}\right)=b_{0}+b_{1} P_{e}+b_{2} P_{g}+b_{3} H D D+b_{4} S T+b_{5} P D+b_{6} O W N+u
$$

The variables in the fuel choice equation that relate to the heating requirements of the residence have not generally been included in previous 
studies of the subject. This could result in a misspecification of the model, as these factors will determine the intensity of the heating equipments use, and thus, the significance of the first costs of the equipment. The dumm variable for owner occupied houses (OWN) will capture differences between information and discount rates for the two classes of consumers and thus, the importance of initial capital costs.

The thermal efficiency of the residence is also endogenous to the energy demand model. The optimal level of efficiency for the house is determined by the available technology, the climate of the area, and the costs and benefits of high levels of efficiency. Equation 5.11 specifies the level of thermal efficiency $(\theta)$ as a function of the price of fuel $\left(P_{e}\right.$ and $\left.P_{g}\right)$, heating degree days (HDD), cooling degree days (CDD), age of the structure (AGE) and the price of building materials $\left(P_{m}\right)$. The age of the structure (AGE) serves as a proxy variable for the technology and the price of building materials represent the costs of improving the structure's thermal efficiency. There is one other variable which will impact the consumers' choices of efficiency characteristics of the structure. This is the selection of primary heating fuel. The type of insulation varies systematically with the heating fuel. Thus, Equation 5.11 contains a dummy variable $\left(F_{g}\right)$ equal to one if the residence uses natural gas as their primary heating fuel.

$$
\begin{aligned}
\ln = & \ln b_{0}+b_{1} \ln P_{e}+b_{2} \ln P_{g}+b_{3} \ln Y+b_{4} \ln H D D \\
& +b_{5} \ln C D D+b_{6} \ln A G E+b_{7} \ln P_{m}+b_{8} F_{g}+v
\end{aligned}
$$

Air conditioning is one of the major energy using appliances in the home and it contributes significantly to peak period demands. The choice to acquire air conditioning equipment is considerd explicitly below (Equation 5.12). The decision to air condition a residence is determined by the price of electricity $\left(P_{e}\right)$, household income $(Y)$, cooling degree days (CDD), age of the structure (AGE), and a dummy variable for owner occupied housing (OWN). Since consumers have the option of air conditioning all or only part of their residence, this stock decision is broken into two sequential decisions. The first is whether consumers have any air conditioning. Given the consumer decides to purchase air conditioning the second decision is whether to purchase central or room air 
conditioning. Each equation is specified with basically the same explanatory variables. The equation for central air conditioning is 5.13. The number of gas air conditioners is relatively small, thus only electric air conditioners were considered.

$$
\begin{aligned}
& A C=b_{0}+b_{1} P_{e}+b_{2} C D D,+b_{3} Y+b_{4} A G E+b_{5} O W N+\varepsilon \\
& C A C=a_{0}+a_{1} P_{e}+a_{2} C D D+a_{3} Y+a_{4} A G E+a_{5} O W N+\varepsilon
\end{aligned}
$$

The last segment of the residential energy demand model describes the households acquisition of a stock of other energy using appliances. However, since the primary objective of this analysis was to estimate fuel prices elasticities for heating and cooling, the stock of other energy using appliances was not estimated. The arguments of this equation do not significantly interact with the parameters in the model's other equations.

In summary, the model presented above can be described as a block recursive system. The type of fuel and level of thermal efficiency are simultaneously determined. Air conditioning and the stock of other appliances are selected by consumers independent of other energy related decisions. Then with the stock and characteristics of appliances taken as given, a residential energy demand function is estimated. The stock of energy using appliances is assumed to be durable and the consumer does not adjust rapidly. Therefore, the estimated price elasticity of energy demand will represent the consumers' short run responsiveness to energy price changes. Given the objective of the study was to estimate consumer response to improved (and fixed) themal efficiency, this short run response is appropriate. For the other equations in the model, the prices of energy are assumed to reflect the long run geographical structure of prices. Thus, the consumers' choices more closely represent long run equilibrium positions.

The energy demand model can be used to predict the change in residential energy usage for a large number of consumer groups and cl imate zones. Separate energy price elasticities for both heating and cooling can be derived. In addition, the el asticity estimates will vary by type of fuel and by heating or cooling requirements. Theoretically, the elasticities vary for each level of 
heating degree days or cooling degree days. Because these are continuous variables such specific estimates are untractable. Thus, each of these variables can be grouped and then elasticities could be computed at the midpoints of the groups.

From the results presented in the section on Energy Efficiency and Space Conditioning Energy Demand (Section 3.0) the change in energy demand due to conservation programs can be from the estimated price elasticity of demand. Recall that for a one percent change in efficiency, the quantity of energy demanded will change by minus one the space conditioning fuel price elasticity of demand minus one. After the econometric estimates are completed, the residential energy demand impact of conservation programs can be estimated for a broad cross-section of households by $\mathrm{cl}$ imate, price level and income. 


\subsection{THE THERMAL EFFICIENCY INDEX AND OTHER VARIABLES IN THE MODEL}

This section describes the data used to statistically estimate the energy demand model presented in the previous section. This section is divided into five parts. The first describes the National Inter im Energy Consumption Survey (NIECS). The data from this survey was the only data source used in this project. The second and third parts of this section describe the development of marginal energy prices and a residential shell thermal efficiency index, respectively. The fourth describes the development of electric and gas nonspace conditioning consumption indexes. The final part describes the steps taken to remove extraneous observations from the data set.

\subsection{DESCRIPTION OF THE "NIECS" DATA SET}

The data set used in the empirical analys is that follows (Section 7.0) is the National Interim Energy Consumption Survey (NIECS). This survey was sponsored by DOE's Program Development Office, Energy Information Administration. The Interim survey was used by DOE a as test for a continuing annual residential energy survey. The objective of the program is to develop a representative national data base on residential fuel use, household gasoline use and energy conservation measures adopted by the household.

The NIECS data was collected during the winter of 1978-79 with actual energy purchases obtained for the period between October 1, 1977 and March 31, 1979. The sample design for the survey was a representative area probability sample. The households interviewed were drawn from 456 "blocks" of 25 residences, with approximately 10 or 11 households interviewed in each "block". From the 4507 eligible households selected for the survey personal interviews were obtained for 3842 households and another 239 responded to a mail questionnaire. These households were selected as representative of the contiguous 48 states and District of Columbia. A description of the survey procedure can be found in Residential Energy Consumption Survey: Conservation (U.S. Department of Energy 1980).

One unique feature of the survey was the source of residential fuel data. Each respondent was asked to give written permission for DOE to collect from 
the household's fuel suppliers actual billing data for the residence. Approximately 95 percent of the households granted permission to obtain the information. Data recieved from the fuel suppliers included the quantity and dollar amounts of electricity, gas and/or fuel oil purchased for each billing period. This is a significant advance over other micro-level data sets which have generally relied on the consumer's estimate of his typical monthly bill for electricity, gas or fuel oil consumption.

The survey questionnaire covered several pertinent areas, including characteristics of the residential structure, the heating and cooling systems, energy conservation efforts, the stock of household appliances, and demographic characteristics of the household. Questions related to the residential structure covered the year built, square footage, number of floors, attic insulation, wall insulation, number of windows, storm doors and windows and the estimated market value or rent. Heating and cooling system questions dealt with the type of fuel, primary heating and cooling equipment, and secondary heating equipment. The demographic information included education, family income, household size, marital status, race and the age of each resident.

Tables presented below show the mean response on a few of the key variables (such as fuel consumption, residence size, attic insulation, family income, family size) cross tablulated by housing type and primary heating fuel. Tables 6.1 through 6.5 show the mean responses for single family detached, single family attached, mobile homes, 2-4 unit structures and more than 5 unit structures respectively. (a) Natural gas was used as the primary heating fuel in 58.6 percent of the households. Fuel oil and electricity were used by 22.9 and 18.5 percent of the households respectively.

As expected, there is little variation in the structural and demographic variables across the various heating fuels for each building type. There are differences in the quantity of energy consumed. Consumption, as measured by BTUs, is less for households with electric heat than for gas heating and fuel oil users. This is undoutably due to climatic differences in certain areas which would make electric heat feasible. The observed pattern persists in each

(a) Single family attached structures have a vertical common wall where as 2-4 unit structures have at least one common horizontal wall. 
structure type. Fuel oil uses tend to have the highests BTU requirements between the three fuels. One expection to this is in mobile home residents where natural gas users consume larger quantities than those with fuel oil furnaces. Again the difference in average energy consumption is most likely due to locational differencs.

Interesting comparisons can be made across the different housing types shown in the different tables. As would be expected single family-detached structures tend to be the largest, followed by single family attached structures, mobile homes and 2-4 unit structures. Single family attached and detached structures heating with electricity were, on average, the largest in the sample (see Tables 6.1 and 6.2). Their residents also had the highest

\section{TABLE 6.1. Summary Statistics for Single Family} Detached Residences

\begin{tabular}{|c|c|c|c|}
\hline & Gas Heat & 0il Heat & Electric Heat \\
\hline $\begin{array}{l}\text { Consumption (MBTU) } \\
\text { Primary Heating Fuel } \\
\text { Electricity } \\
\text { TOTAL }\end{array}$ & $\begin{array}{r}145,757 \\
27,421 \\
173,178\end{array}$ & $\begin{array}{r}124,835 \\
34,759 \\
159,594\end{array}$ & $\begin{array}{r}N / A \\
\frac{84,482}{84,482}\end{array}$ \\
\hline $\begin{array}{l}\text { Expenditures } \\
\text { Primary Heating Fuel } \\
\text { Electricity } \\
\text { TOTAL }\end{array}$ & $\begin{array}{l}380.73 \\
372.81 \\
753.54\end{array}$ & $\begin{array}{l}489.46 \\
459.81 \\
948.27\end{array}$ & $\begin{array}{r}\text { N/A } \\
748.97 \\
748.97\end{array}$ \\
\hline Residence Size-Sq. Ft. & 1,539 & 1,617 & 1,687 \\
\hline Number of Rooms & 5.9 & 6.1 & 5.9 \\
\hline Attic Insulation-In. & 5.6 & 5.8 & 6.5 \\
\hline Household Income & $\$ 19,567$ & $\$ 20,316$ & $\$ 21,226$ \\
\hline Household Members & 3.1 & 3.0 & 3.2 \\
\hline Number in Sample & 1,510 & 586 & 368 \\
\hline
\end{tabular}




\section{TABLE 6.2. Summary Statistics for Single Family}

Attached Residences

Gas Heat 0 il Heat Electric Heat

\begin{tabular}{|c|c|c|c|}
\hline $\begin{array}{l}\text { Consumption (MBTU) } \\
\text { Primary Heating Fuel } \\
\text { Electricity } \\
\text { TOTAL }\end{array}$ & $\begin{array}{r}126,734 \\
23,439 \\
150,173\end{array}$ & $\begin{array}{r}124,798 \\
28,482 \\
153,230\end{array}$ & $\begin{array}{r}N / A \\
77,747 \\
77,747\end{array}$ \\
\hline $\begin{array}{l}\text { Expenditures } \\
\text { Primary Heating Fuel } \\
\text { Electricity } \\
\text { TOTAL }\end{array}$ & $\begin{array}{l}386.18 \\
318.67 \\
704.85\end{array}$ & $\begin{array}{l}487.38 \\
383.67 \\
871.05\end{array}$ & $\begin{array}{r}\mathrm{N} / \mathrm{A} \\
\frac{767.91}{767.91}\end{array}$ \\
\hline Residence Size-Sq. Ft. & 1,220 & 1,463 & 1,689 \\
\hline Number of Rooms & 5.6 & 6.8 & 5.7 \\
\hline Attic Insulation-In. & 5.6 & 6.9 & 6.2 \\
\hline Household Income & $\$ 17,047$ & $\$ 17,619$ & $\$ 21,386$ \\
\hline Household Members & 2.9 & 3.3 & 2.9 \\
\hline Number in Sample & 127 & 21 & 22 \\
\hline
\end{tabular}

TABLE 6.3. Summary Statistics for Mobile Homes Gas Heat 0 il Heat Electric Heat

\begin{tabular}{|c|c|c|c|}
\hline $\begin{array}{l}\text { Consumption (MBTU) } \\
\text { Primary Heating Fuel } \\
\text { Electricity } \\
\text { TOTAL }\end{array}$ & $\begin{array}{r}93,704 \\
22,862 \\
116,566\end{array}$ & $\begin{array}{l}60,449 \\
\frac{30,716}{91,165}\end{array}$ & $\begin{array}{r}N / A \\
70,981 \\
70,981\end{array}$ \\
\hline $\begin{array}{l}\text { Expenditures } \\
\text { Primary Heating Fue } 1 \\
\text { Electricity } \\
\text { TOTAL }\end{array}$ & $\begin{array}{l}242.47 \\
313.97 \\
556.44\end{array}$ & $\begin{array}{l}239.30 \\
374.63 \\
613.93\end{array}$ & $\begin{array}{r}\text { N/A } \\
519.94 \\
519.94\end{array}$ \\
\hline Residence Size-Sq. Ft. & 947 & 768 & 885 \\
\hline Number of Rooms & 4.2 & 4.3 & 4.4 \\
\hline Attic Insulation-In. & 5.0 & 5.5 & 4.8 \\
\hline Household Income & $\$ 14,290$ & $\$ 11,062$ & $\$ 12,886$ \\
\hline Household Members & 2.7 & 2.7 & 2.7 \\
\hline Number in Sample & 74 & 72 & 126 \\
\hline
\end{tabular}


TABLE 6.4. Summary Statistics for Residences in 2-4 Unit Structures

Gas Heat 0 il Heat Electric Heat

\begin{tabular}{|c|c|c|c|}
\hline $\begin{array}{l}\text { Consumption (MBTU) } \\
\text { Primary Heating Fuel } \\
\text { Electricity } \\
\text { TOTAL }\end{array}$ & $\begin{array}{r}118,983 \\
14,782 \\
133,765\end{array}$ & $\begin{array}{r}167,527 \\
16,553 \\
184,080\end{array}$ & $\begin{array}{r}N / A \\
48,851 \\
48,851\end{array}$ \\
\hline $\begin{array}{l}\text { Expenditures } \\
\text { Primary Heating Fuel } \\
\text { Electricity } \\
\text { TOTAL }\end{array}$ & $\begin{array}{r}344.04 \\
231.18 \\
575.22\end{array}$ & $\begin{array}{l}664.35 \\
162.20 \\
826.50\end{array}$ & $\begin{array}{r}\text { N/A } \\
507.21 \\
507.21\end{array}$ \\
\hline Residence Size-Sq. Ft. & 902 & 981 & 908 \\
\hline Number of Rooms & 4.5 & 4.7 & 3.9 \\
\hline Attic Insulation-In. & 4.8 & 4.9 & 7.6 \\
\hline Household Income & $\$ 11,517$ & $\$ 13,818$ & $\$ 15,985$ \\
\hline Household Members & 2.5 & 2.6 & 2.1 \\
\hline Number in Sample & 319 & 99 & 67 \\
\hline
\end{tabular}

TABLE 6.5. Summary Statistics for Residences in 5 or More Unit Structures

Gas Heat $\quad$ il Heat Electric Heat

\begin{tabular}{|c|c|c|c|}
\hline $\begin{array}{l}\text { Consumption (MBTU) } \\
\text { Primary Heating Fue } 1 \\
\text { Electricity } \\
\text { TOTAL }\end{array}$ & $\begin{array}{l}64,116 \\
10,635 \\
74,751\end{array}$ & $\begin{array}{r}126,237 \\
7,800 \\
134,037\end{array}$ & $\begin{array}{r}N / A \\
46,819 \\
46,819\end{array}$ \\
\hline $\begin{array}{l}\text { Expenditures } \\
\text { Primary Heating Fue } 1 \\
\text { Electricity } \\
\text { TOTAL }\end{array}$ & $\begin{array}{l}184.57 \\
175.13 \\
359.70\end{array}$ & $\begin{array}{l}500.75 \\
176.30 \\
677.05\end{array}$ & $\begin{array}{r}\text { N/A } \\
\frac{472.81}{472.81}\end{array}$ \\
\hline Residence Size-Sq. Ft. & 749 & 399 & 1,083 \\
\hline Number of Rooms & 3.8 & 3.0 & 3.9 \\
\hline Attic Insulation-In. & $N / A$ & $N / A$ & $N / A$ \\
\hline Household Income & $\$ 13,088$ & $\$ 12,191$ & $\$ 17,988$ \\
\hline Household Members & 1.9 & 2.5 & 2.0 \\
\hline Number in Sample & 211 & 97 & 126 \\
\hline & 6.5 & & \\
\hline
\end{tabular}


incomes, $\$ 21,226$ and $\$ 21,386$ for detached and attached structures, respectively. The highest mean value for attic insulation was 6.9 inches in oil heated single family attached units. $0 i 1$ heated homes tend to have the highest energy budgets, which is probably the result of high heating degree level and higher energy prices. Homes heated with electricity also had high levels of insulation.

\subsection{DERIVATION OF GAS AND ELECTRIC MARGINAL PRICES}

In order to achieve the primary objective of this research, estimates of space conditioning fuel price elasticities for electicity and gas are required. (A space conditioning fuel price elasticity is defined as the percent change in the quantity of energy demanded for space conditioning due to a one percent change in the price of the fuel used to space condition.) The appropriate way to estimate these price elasticities is to specify and empirically estimate an energy demand equation. The empirical results can then be used to determine the relationship between changes in the thermal efficiency and energy demanded for space conditioning holding other factors constant.

These estimated price elasticities will be sensitive to how price is measured. Because of the way electricity and gas have historically been sold in the U.S. different price measures could be derived. The following paragraphs describe these price measures and their implications for estimating price elasticities.

\subsubsection{Theoretical Explanation of the Need for Marginal Price}

For most goods the specification of the price variable in a demand equation involves no unusual problems. The market price of the good, which is essentially constant for all quantities consumed, is used in the analysis. However, electricity and gas are not priced in a usual manner. These goods are block priced. Typically, increases in the quantity consumed, past the boundaries of a given block, cause the per unit price of the additional units to be lower.

With a declining block rate for residential electricity and natural gas, consumers pay a fixed charge (FC) and then a series of per unit charges for 
specified quantity intervals $\left(x_{a}-x_{b}\right)$. Specifically, a consumers bill (C) would be computed as follows:

$$
\begin{aligned}
& C=F C+P_{1} X, \quad \text { where } 0 \leq X<X_{1} \\
& C=F C+P_{1} X_{1}+P_{2}\left(X-X_{1}\right), \quad \text { where } X_{1} \leq x<x_{2} \\
& C=F C+\sum_{i} P_{i} x_{i}+P_{n}\left(x-x_{n-1}\right), \quad \text { where } x_{n-1} \leq x \leq \infty \text {. }
\end{aligned}
$$

where $P_{i}$ represents the price for quantity interval $i$ and $x$ represents the total quantity of energy consumed.

Consumer response to changes in a natural gas or electric rate structure depends upon the way in which the rate structure changes. Increases in the marginal price of energy will cause one type of consumption response whereas increases in the fixed charge or the prices for non-marginal blocks will cause another type of response. Thus, a model of energy demand should consider separately the relationship between marginal price changes and energy demand, and the relationship between non-marginal price changes and energy demand. The reasons for the different response to marginal and non-marginal price changes are considered below.

A declining block price schedule causes the budget constraint faced by each consumer to be piecewise linear. If the declining block schedule has three blocks then the budget constraint might look similar to line $A B C D$ in Figure 6.1. Theoretically, the consumer decides what quantity of energy (point $E$ in Figure 6.1) and other goods to consume by finding the point of tangency between the budget constraint and the highest indifference curve.

Consider two different types of changes in the declining block schedule. First, consider an increase in the fixed charge paid by consumers. This will 
cause a downward shift in the budget constraint so that the new budget constraint will become $A^{\prime} B^{\prime} C^{\prime} D^{\prime}$. Note that the quantity of energy consumed will decrease as a result of the price structure change (from $E$ to $E^{\prime}$ ). The change in the quantity consumed results entirely from an income effect; there is no substitution effect. The price change only reduces the real income of the consumer thereby causing an income effect. The price change does not effect the marginal price of energy, and, as a result, the consumer does not substitute between energy and other goods.

Second, consider an increase in the second block price (the marginal price). This price change will cause a shift in the consumers budget line to $A B C$ 'D''. The quantity of energy consumed would decrease from $E$ to $E$ ". This change in consumption would be caused by both an income and substitution effect. It follows that only a change in the marginal price of energy will cause both an income and substitution effect.

The marginal price of energy is often not easily observable. As a result other measures of energy price have often been used in empirical energy demand analyses. Because of the nature of the data collected from utilities, information on total consumer energy costs and the total quantity consumed is often available. As a result average price has often been used as a price variable.

Much has been written about the inadequacies of average cost in an energy demand analys is (Taylor 1975, Acton et al. 1976). Consider Figure 6.2; AP represents the average price curve, $M$ P represents the marginal price $f$ aced by the individual. In the initial condition a consumer has demand curve $D$ and consumes quantity $E$. Assume that for some reason the consumer's demand for energy increases to $D^{\prime}$ and as a result consumption increases to $E^{\prime}$. Over this span the average price of energy decreased from AP1 to AP2, while the marginal price of energy did not change. A model based on average price would ascribe part on the difference in consumption ( $\left.D^{\prime}-D\right)$ to a change in price, whereas consumer theory indicates that because marginal and non-marginal price did not change, the consumption change had nothing to do with price. Thus, use of average price will cause the energy own-price elasticity estimates to be biased. Given that one of the primary goals of this study is to accurately estimate a space conditioning fuel price elasticity, it follows using marginal price rather than average price in the empirical analysis would have significant benefits. 


\subsubsection{Marginal Price Derivation}

The following paragraphs describe alternative methods that could potentially be used to calculate the marginal price of energy to a consumer. Three alternative methods will be discussed: 1) using the rate books, 2) using regression analysis, and 3) using a direct calculation approach.

\subsubsection{Rate Book Approach}

Information on the rate schedules for all gas and electric utilities is published annually. Given information on the quantity of energy consumed by any individual, these rate books could be used to determine the marginal price paid by the consumer. The NIECS file provides information on the quantity of energy consumed but there is no information on the utility used by the consumer. Thus, there is no direct way of using the rate books to determine maginal price.

\subsubsection{Regression Analys is Approach}

Billing period information is available for some of the individuals in the NIECS data file. The billing period data contains information on quantity and cost for electricity and gas by billing period. Quantity and cost information is available for 13 months for most of the sample.

This informtion could be used in at least a couple of ways to estimate marginal price for each consumer. Within the regression analysis approach, the a consumer's total bill for a fuel in each period is regressed on the quantity of energy consumed. If the relationship between cost and quantity was linear, then the estimated regression slope (the beta coefficient on quantity) would equal the marginal price $f$ aced by the consumer.

Unfortunately the cost, quantity relationship is not linear. The declining block schedule causes a piecewise linear relationship. Thus, using this approach will produce a biased maginal price estimate, where the extent of the bias depends on the number of blocks and the difference between each block.

\subsubsection{Direct Calculation Approach}

The billing period information could be used in another way to estimate marginal price. Consider a household that had a small quantity change between two billing periods. The difference in cost between the two bills could be 
divided by the difference in quantity between the two bills to determine the marginal price for the difference in quantity. Using this approach would require the following assumptions: 1) the small quantity change did not cause the consumer to jump from one rate block to another, and 2) the rate structure did not change between the billing periods.

A variant on this approach could also be used. Within the NIECS file each respondent is grouped according to sampling unit. Sampling unit information can be used to determine groups of respondents that purchase energy from the same utility. The difference between the total bill and quantity for one respondent could be subtacted from the corresponding bill and quantity for another respondent purchasing energy from the same utility. As before, the difference in cost could be divided by the difference in quantity to estimate a marginal price for both respondents. This approach has the advantage that any change in the rate structure within the relevant billing period would be common to both respondents, and as a result, the marginal price estimate would be a weighted average of the before and after marginal price. (a) However, using this approach would require the assumption that the common utility respondents are purchasing within the same rate block.

Given the relative strengths and weaknesses of the approaches described above and the data constraints, it was decided that the direct calculation approach would be used to estimate marginal price. The following section gives a detailed description of the way this approach was used.

\subsubsection{Marginal Price Estimation}

In order to achieve the objectives of this study marginal prices are required for electricity and gas. Recall from the discussion in the previous section that billing period information on cost and quantity is available and that it is possible to identify groups of consumers that purchase their energy from the same utility. This information was used in seven steps to estimate electric and gas marginal prices.

(a) Typically, this will not be a problem because rate charges are often made between billing periods. 
In order to derive an accurate estimate of marginal price using bill and quantity information from different consumers purchasing energy from the same utility, steps must be taken to insure that the consumers lie within the same rate block. As a result the first step in the marginal price estimation process was to divide the NIECS sample into to similar energy end use categories. The categories used for electricity were: 1) electric heat, 2) non-electric heating, 3) electric central air conditioning, 4) room air conditioning, and 5) non-air conditioning. Obviously, some houses could fall into more than one category. The only category for natural gas was natural gas heat. In the NIECS sample every home that used natural gas in any way used it to heat.

It was hypothesized that house size would also be an important variable to control for when attempting to identify common utility households consuming within the same rate block. Thus, in the second step the NIECS sample was further subdivided into single family detached houses and other residential units. As a result of steps one and two, electric heated houses were divided into 10 different categories; natural gas heated houses were divided into two categories.

The third step involved determining which households within each of the 10 electric groups and the two natural gas groups purchased their electricity and/ or natural gas from the same utility. Each of the 10 electric and 2 natural gas groups was further subdivided into common utility/end use (CU/EU) groups. There are within the sample over 450 groups that purchase their energy from the same utility. Thus, over 5000 groups could have been derived. Far less than 5000 were produced because often households within a common utility group had the same end use characteristics (e.g., the houses were all single family detached with natural gas heat).

In the fourth step the billing period information was assigned to a particular month. If a billing period began after the 15th of a month then the cost and quantity information was assigned to the following month. If a billing period began on or before the 15th of a month then the cost and quantity information was assigned to the same month. This was done regardless of the billing period length. (Billing period length is unimportant as long as each CU/EU group has approximately the same billing period length for any particular month.) 
In the fifth step monthly marginal prices were calculated for each CU/EU group. Households within each CU/EU group were arbitrarily ordered. The difference in monthly billing period cost between the first and second households was calculated and divided by the difference in billing period quantity for the same month and the same two households. This was done for all relevant months. Following this, monthly marginal price estimates were calculated for the second and third households and so on until the maximum number of marginal prices for a CU/EU group were calculated. If the CU/EU group had 10 members, and had quantity, cost data for 6 months, then 54 marginal prices would have been calcul ated.

In the sixth step an average marginal price for each CU/EU group and each month was calculated. (Not all monthly prices within a CU/EU group were equal because of cost and quantity rounding.) For a given month the marginal prices calculated in the fifth step were divided by the total number of households in the CU/EU group minus one to derive a monthly average marginal price estimate. After this step ten electric marginal price variables have been derived (one for each of the ten subgroups derived in steps one and two) and two natural gas marginal prices have been derived for as many months as each CU/EU group had quantity and cost data.

In the final step the monthly marginal prices derived for each CU/EU group were assigned back to each household. Each house within a CU/EU group was assigned marginal prices for the relevant months based on the heating equipment, cooling equipment and building type characteristics of the house. One electric price was assigned to each CU/EU group. A natural gas price was assigned only to CU/EU groups that used natural gas to heat. If the house had any type of air conditioning then during the cooling season air conditioning marginal prices were assigned to the house. If the house did not have air conditioning then non-air conditioning marginal prices were assigned for the cooling season. The same type of procedure was used for electric heating. Nonelectric heating electric marginal prices were assigned to houses that used natural gas to heat.

Census region average marginal prices for the winter of 1978-79 and the summer of 1978 are provided in Table 6.6. Winter prices are averaged over the 
TABLE 6.6. Average Marginal Prices by Census Region

\begin{tabular}{|c|c|c|c|c|}
\hline $\begin{array}{l}\text { Census } \\
\text { Region }\end{array}$ & $\begin{array}{c}\text { Winter } \\
\text { Electric } \\
\text { Price } \\
\text { (Cents/kwh) } \\
\end{array}$ & $\begin{array}{c}\text { Summer } \\
\text { Electr ic } \\
\text { Price } \\
\text { (Cents/kWh) } \\
\end{array}$ & $\begin{array}{c}\text { Winter } \\
\text { Natural } \\
\text { Gas } \\
\text { Price } \\
\text { (\$/MCF) } \\
\end{array}$ & $\begin{array}{c}\text { Surmer } \\
\text { Natural } \\
\text { Gas } \\
\text { Price } \\
\text { (\$/MCF) } \\
\end{array}$ \\
\hline Nor theast & 4.80 & 5.08 & 2.99 & 3.29 \\
\hline Midwest & 4.32 & 4.37 & 2.36 & 2.49 \\
\hline South & 3.56 & 3.80 & 2.53 & 2.92 \\
\hline West & 3.25 & 3.05 & 2.31 & 1.99 \\
\hline
\end{tabular}

months of November through February. Summer prices are averaged over the months of June through August.

\subsection{MEASURING THE EFFICIENCY OF THE STRUCTURE}

One of the most important features of this residential energy demand study is the explicit treatment of efficiency of energy utilization. When such efficiency is endogenous, failure to include it in the specification of the model will bi as the estimated energy price elasticity of demand. Warren-Boulton (1978) has shown that in general when estimating the demand for variable factors their own-price elasticities will be biased toward unity unless the level of efficiency is included in the model. Thus, the estimation of residential energy demand for space conditioning is critically dependent on the thermal efficiency of the housing structure. In the following paragraphs a method of measuring thermal efficiency is described.

To construct an index of thermal efficiency DOE-2 Building Thermal Analysis Program was used. DOE-2 and the accompanying Building Design Language was developed by the U.S. Department of Energy for architects and engineers as an aid to designing energy efficient buildings. The computer program is capable of calculating the hourly, daily, monthly and annual energy requirements to maintain a building within a specified temperature range. By performing parametric runs for alternative building characteristics the energy requirements can be measured for each alternative. With the residential structure characteristics given in the NIECS data set, the baseling energy requirements for heating and cooling each residence could be estimated. Because the NIECS data 
set did not include information on all of the inputs to DOE-2 some assumptions were maded, such as the height of the building or the size of windows. The input variables and asumptions used in running DOE-2 are discussed in Appendix A.

Because of the detailed calculations and output from DOE-2, it was prohibitively expensive to run the DOE-2 program for each residence in the NEICS data set. Therefore, the algorithm for calculating annual energy usage was estimated using mutiple regression techniques. First a random sample of 250 residences was selected from the NIECS data set. The sample was stratified into 200 single family structures and 50 multi-family structures. The characteristics of these residences were inputed into DOE-2 to estimate the energy requirements for heating the structure based on the weather conditions for a typical year in St. Louis, Missouri.

The natural $\log$ of the estimated BTU requirement was then regressed on the log of the glass surface area (LGAREA) which included windows and sliding glass doors, the percent the glass area with storm windows (PSAREA), the number of doors (DOORS), the percent of doors with storm doors (SDOOR), the log of the square feet in the residence (LSQFT), the $\log$ of the number of inches of attic insulation (LATINS), a dumy variable for wall insulation (WLINS), a dumy variable if it was a second story (FLOOR2), a dummy variable for duplex (DUPL), and a dumy variable for a 3-4 unit structure (QUAD). Equation 6.1 gives the parameter estimates derived from the regression.

$$
\begin{aligned}
\ln (\text { MBTU })= & -2.614+0.099 \text { LGAREA }+0.832 \text { LSQFT }-0.113 \text { LATINS } \\
& -0.002 \text { PSAREA }+0.0289 \text { DOORS }-0.0154 \text { SDOOR } \\
& -0.540 \text { WLINS }-0.102 \text { FLOOR2 }-0.576 \text { DUPL }-1.211 \text { QUAD } \\
& \text { R-Square }=0.851 \quad N=250
\end{aligned}
$$

This equation was used to predict the BTU requirement for each residence in the NIECS survey. Our measure of the structure's energy efficiency $(\theta)$ was then computed by dividing the predicted BTU requirement per square foot of floor area into the overall sample mean BTU per square foot. Thus, a residence that is twice as effecient as the average structure would have a $\theta$ value of 
2.0, and a residence that is one half as efficient as the average structure would have a value 0.5 . The assumption used in running DOE-2 and the construction of the efficient index are described more fully in Appendix $A$.

\subsection{ELECTRIC AND GAS APPL IANCE INDEXES}

Correct specification of the energy demand equations required the development of variables that measure nonspace conditioning appliance consumption. Nonspace conditioning appliance consumption indexes were developed for electric and natural gas appliances. The indexes were developed by summing average appliance energy usage for all nonspace conditioning appliances present in the household. Electric appliance average consumption information was taken from "Annual Energy Requirements of Electric Household Appliances," which is published by Edison Electric Institute. Gas appliance average consumption information was taken from "Gas Facts," which is published by American Gas Association.

\subsection{OBSERVATIONS DELETED FROM THE DATA SET}

Observation from residents of $5+$ unit structures were excluded from further empirical analysis for several reasons even though their exclusion reduces the generallity of the results. First, most of the energy consumption data were estimated for these households. Second, a very small proportion of the respondents in the category could answer the question pertaining to the size the living space. Further, no information was available for the insulation characteristics of the structures. Both of these variables were important in the estimate of the efficiency of the structure. Thus, too few observation had sufficient data to include the category in the sample.

Several other categories of observations also were excluded from the data set. Those households using fuel oil as the primary heat fuel were not included. Because there are significant variations in household storage of fuel oil it was impossible to determine the quantity of energy consumed. Thus, it was impractical to attempt any estimates of the fuel oil price elasticity of demand. Households whose bills were estimated by the Energy Information Administration were also deleted from the data set. A few respondents had only annual consumption data and no billing period data, and those observations were also dropped from the data set. 


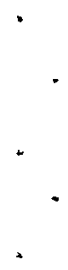

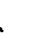




\subsection{ECONOMETRIC ESTIMATION OF THE MODEL}

Section 5 presents the development and specification of a residential energy demand model. The objective of this section is to describe the empirical tests of the model using the NIECS data set. The model and its econometric application is divided into two parts. The first part determines the short-run response of residential energy consumers to price and "technology" changes. The major emphasis is placed on this part of the model as the elasticities derived from this analysis are used to estimate the impact of thermal efficiency improvements on residential energy demand. Demand equations are estimated for winter electric space heating, winter natural gas space heating and summer electric air conditioning. The second part of the model examines the stock of space conditioning appliances acquired by households. This includes analyses of primary heating fuel choice, thermal efficiency choice, the probability of having air conditioning, and the probability of having central air conditioning given the household has some type of air conditioning.

Marginal fuel prices were used in the empirical estimation. They were computed using household billing data to approximate the marginal cost of using one more unit of the fuel. Since utility consumers do not directly see this price, it has been a matter of debate in the economic literature what is the appropriate measure of prices. Parti and Parti (1980), for example, argue that the average charge per kilowatt hour from the previous period is a reasonable value for the price used by consumers in allocating their budgets. However, it is assumed in this analysis that residential consumers are cognizant of the marginal cost of utility services and respond accordingly. As households make adjustments in consumption, they typically remain on the same rate block, thus, they experience a change in their bill governed by the marginal price. Thus, there is reason to believe that households are cognizant of marginal price.

A unique feature of this analysis is the introduction of a thermal efficiency index in the model of residential energy demand. The omission of efficiency characteristics can bias the estimated price elasticities for energy or any other production input (Warren-Boulton 1978). The thermal efficiency of each residence is defined as the ratio of the projected Btu requirement per 
square foot of living space to the Btu requirement for the mean residence. The projected energy usage is derived from an engineering model of residential space heating requirements (see Section 6.0).

The functional forms for the energy demand equations have not been derived from economic theory. Rather, they have been selected for their generality. The abbreviated form of the translog function used in this analysis imposes few a priori constraints on the key variables being tested in the model. Because the exact form of the demand equations is not fixed by theory, the estimated elasticities should be viewed as approximations to the true paramaters. However, the flexibility of the estimated equations along with consistant results suggest they are reasonably accurate. In the following paragraghs, the short run energy demand elasticities estimates are discussed and then the long run space conditioning appliance stock demand equations are presented.

\subsection{ENERGY DEMAND EMPIRICAL RESULTS}

The empirical objectives of this study were to estimate space conditioning fuel price elasticities and thermal efficiency energy demand elasticities. It was shown in Section 3.0 of this report that economic theory suggests that the price elasticity and efficiency elasticity will add to 1 . Thus, either elasticity could be used to calculate the impact of a change in thermal efficiency on space conditioning energy demand. The required elasticities were derived by statistically estimating residential energy consumption equations. Results for electric air conditioning, gas heating, and electric heating are described below.

\subsubsection{Electric Air Conditioning}

As described in Section 5.0, a variant on the translog equation was used to estimate summer electric consumption (summer is defined here as including the months of June, July and August). Several alternative specifications were attempted. When many terms from the full translog were included in the specification, multicollinearity problems caused non-BLU (best linear unbiased) regression parameters. Several different specifications were tried in an

attempt to find a specification that provided BLU regression estimates and accurate estimates of the air conditioning fuel price and effeciency elasticities. The following specification was selected. 


$$
\begin{aligned}
& \ln E_{s, j}=a_{0}+\sum_{j} b_{j} W Z_{i}{ }^{\star}\left(\operatorname{lnCDO}{ }_{j} / \ln P e_{e, j}\right)+\sum_{j} b^{\prime}{ }_{i} W Z_{i}{ }^{*} \ln \theta_{j} \\
& +b_{13} \ln Y_{j}+b_{14} \operatorname{lnRM_{j}}+b_{15} \operatorname{lnP} e, j{ }^{\star} \operatorname{lnEAX} x_{j}+e \\
& (i=1,2,3,4,6,7) \\
& (j=1, \ldots, n)
\end{aligned}
$$

where

$$
\begin{aligned}
E_{s, j}= & \text { average summer electric consumption per day for household } j \\
& \text { (June, July, August 1977) } \\
W_{i}= & \text { dummy variable for weather zone } i \text { (for example, } W Z_{2} \text { equals } 1 \\
& \text { if household in located in weather zone } 2 \text {, otherwise } \mathrm{WZ}_{2} \text { equal } \\
& \text { 0) (The U.S. has been divided into seven weather zones as shown } \\
& \text { in Figure 1) } \\
\mathrm{CDD}_{j}= & \text { average cooling degree days per day for household } j \text { (June, } \\
& \text { July, August 1977) } \\
\mathrm{P}_{\mathrm{e}, j}= & \text { the average of the (consumer) marginal prices of electricity } \\
& \text { for household } j \text { in June, July, August } 1977 \\
\theta_{j}= & \text { index of shell thermal efficiency for household } j \text { (see Section } \\
& 6 \text { for a complete description of this variable) } \\
Y_{j}= & \text { annual family income for household } j \\
\mathrm{RM}_{j}= & \text { number of rooms in the housing units occupied by household } j \\
E A X_{j}= & \text { electric appliance index that equals average KWH usage for all } \\
& \text { non-space conditioning appliances in household } j \text { (see Section } 6 \\
& \text { for a complete description of this variable). }
\end{aligned}
$$

There are several desirable properities associated with this specification. First, the weather zone, price, cooling degree day interaction terms allow the generation of price elasticity estimates that can vary by climate zone and cooling degree days. Second, the weather zone, thermal efficiency interaction terms allow the generation of efficiency elasticity est imates that can vary by $\mathrm{cl}$ imate zone. Third, the price, electric appliance index interaction term extracts the relationship between price and utilization of non-air conditioning appliances from the price, weather zone, cooling degree day interaction terms. Thus, the price elasticity estimates derived from the 
weather zone, price, cooling degree day interaction terms are for air conditoning only.

Fourth, it is pointed out within the specification chapter that assessing the energy consumption impact of conservation programs requires an estimate of the short run space conditioning fuel price elasticity of demand. The short run price elasticity measures how consumers change space conditioning appliance usage (mainly through altering the internal temperature) due to fuel price changes. By definition, within the short run consumers cannot alter the stock of space conditioning appliances. This is the apppropriate elasticity to use to assess the impact of conservation because the consumer responds to increased efficiency by altering appliance usage as opposed to altering the appliance stock. Equation 7.1 includes information on the stock of appliances within the houselhold; thus, this specification will provide an estimate of the relationship between consumption and fuel price holding appliance stock constant (i.e., the short run air conditioning fuel price elasticity of demand).

Equation 7.1 was estimated for all households in the sample that have some type of air conditioning (either room or central). (a) Empirical results are provided in Table 7.1. The specification provides direct estimates of elasticities for income and structure size. The results indicate that the income elasticity of demand (the percentage change in the quantity of electricity demanded due to a one percent change in family income) is 0.24 . (b) In addition, a 10 percent increase in the number of rooms in a residence will increase consumption by 4.6 percent.

The regression coefficients on the efficiency, weather zone interaction terms are the efficiency elasticities for the corresponding climate zone. Price elasticity estimates were derived from the weather zone, price, cooling degree day interaction terms using mean cooling degree days within a climate

(a) The data does not contain any observations from climate zone 5 thus the corresponding interaction terms were excluded from the equation.

(b) Electricity income elasticity estimates derived in some previous studies are:

Parti and Parti: 0.15

Wilder and Willenborg: 0.16

Acton, Mitchel1 and Mowill: 0.40 to 0.41

Taylor, Blattenburger and Verleger: 0.0004 to 0.38 
TABLE 7.1 Electric Air Conditioning Empirical Results

\begin{tabular}{|c|c|c|}
\hline Variable & $\begin{array}{l}\text { Regression } \\
\text { Coefficient (b) } \\
\end{array}$ & $\begin{array}{l}\text { Standard } \\
\text { Error of b }\end{array}$ \\
\hline Intercept & 0.051 & 0.213 \\
\hline$W Z_{1} *\left(\operatorname{lnCDO}{ }_{j} / \operatorname{lnP} e_{e, j}\right)$ & $0.066^{(b)}$ & 0.030 \\
\hline$W Z_{2}^{*}\left(\operatorname{lnCDO}{ }_{j} / \ln P\right.$ e,j $)$ & $0.055^{(c)}$ & 0.030 \\
\hline $\mathrm{WZ}_{3}{ }^{*}\left(\operatorname{lnCDD_{j}/\operatorname {ln}\mathrm {P}} \mathrm{e}, \mathrm{j}\right)$ & $0.134^{(a)}$ & 0.031 \\
\hline$W Z{ }^{\star}\left(\operatorname{lnCDD}{ }_{j} / \ln P(e, j)\right.$ & $0.167^{(a)}$ & 0.024 \\
\hline$W Z_{6}{ }^{\star}\left(\operatorname{lnCDD}{ }_{j} / \ln P(e, j)\right.$ & $0.318^{(a)}$ & 0.030 \\
\hline$W Z_{7}^{\star}\left(\operatorname{lnCDD}{ }_{j} / \operatorname{lnP} e, j\right)$ & $0.280^{(a)}$ & 0.029 \\
\hline$W Z_{1}{ }^{\star} \ln \theta_{j}$ & $-0.578^{(a)}$ & 0.116 \\
\hline$W Z_{2}{ }^{\star} \ln \theta_{j}$ & $-0.347^{(a)}$ & 0.081 \\
\hline$W Z_{3}{ }^{\star} \ln \theta_{j}$ & $-0.270^{(a)}$ & 0.061 \\
\hline$W Z_{4} * \ln \theta_{j}$ & 0.95 & 0.090 \\
\hline$W Z_{6}{ }^{\star} \ln \theta_{j}$ & -0.40 & 0.137 \\
\hline$W Z z^{\star} \ln \theta_{j}$ & 0.166 & 0.227 \\
\hline $\operatorname{lnY}{ }_{j}$ & $0.240^{(a)}$ & 0.023 \\
\hline $\operatorname{lnRM_{j}}$ & $0.463^{(a)}$ & 0.065 \\
\hline $\ln P_{e, j} \ln E x x_{j}$ & $-0.008^{(b)}$ & 0.003 \\
\hline \multicolumn{3}{|l|}{$R^{2}=0.274$} \\
\hline$F=41.77$ & & \\
\hline Observations $=1,679$ & & \\
\hline
\end{tabular}

(a) Significant at $1 \%$ level.
(b) Significant at $5 \%$ level.
(c) Significant at $10 \%$ level. 
zone. (a) The air conditioning fuel price elasticity estimates and the thermal efficiency estimates are provided in Table 7.2. The price elasticity estimates vary from -0.08 to -0.51 and, in general, the elasticity estimates increase moving from northern $c l$ imates to southern climates. The thermal efficiency elasticity estimates vary from -0.58 to 0 , and these elasticity est imates decrease from northern $\mathrm{climates}$ to southern $\mathrm{climates.}$

The air conditioning price and efficiency elasticity estimates support the theoretical predictions discussed in Section 2.0. First, the price and efficiency elaticities vary inversely. Theoretical analys is of the fuel price and efficiency elasticities suggests that they should add to one. Obviously this implies the elasticities should vary inversely. Second, the price elasticities are larger in higher cooling degree day areas. In higher cooling degree day areas air conditioning expenditures will be a 1 arger percentage of the household budget. Economic theory indicates that this should cause the air conditioning fuel price elasticity to be larger in higher cooling degree day areas.

The price and efficiency elasticities do not add exactly to one for any cl imate zone as suggested by the theoretical analysis. In the opinion of the authors the main reason for this result is not anomalous behavior but inadequacies of the data set that result in the inability to precisely estimate the residential thermal efficiency index (see Section 6.0).

The space conditioning price and efficiency estimates provide upper and lower bounds for estimating the impact of increasing residential shel 1 thermal efficiency. For example, in climate zone 6, the price elasticity estimate

(a) Price elasticities were calculated with the following formula:

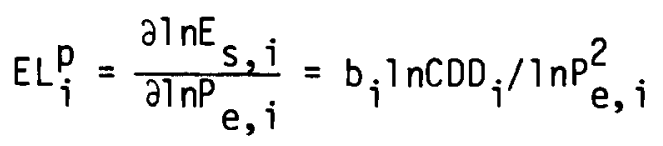

where $E L_{i}^{p}=$ air conditioning fuel price elasticity of demand for weather $E_{S, i}=\begin{aligned} & \text { average summer electric consumption per day for weather } \\ & \text { zone } i\end{aligned}$

$\mathrm{CDO}_{i}=$ mean $\operatorname{COD}$ for weather zone $i$

$\mathrm{P}_{\mathrm{e}, i} \mathrm{i}=$ mean electric $\mathrm{P}$ for weather zone $i$ 
TABLE 7.2. Air Conditioning Price and Efficiency Elasticity Estimates

\begin{tabular}{|c|c|c|}
\hline $\begin{array}{l}\text { Weather } \\
\text { Zone } \\
\end{array}$ & $\begin{array}{c}\text { Price } \\
\text { Elasticity }\end{array}$ & $\begin{array}{l}\text { Efficiency } \\
\text { Elasticity }\end{array}$ \\
\hline 1 & -0.08 & -0.58 \\
\hline 2 & -0.07 & -0.35 \\
\hline 3 & -0.15 & -0.27 \\
\hline 4 & -0.29 & $0^{(a)}$ \\
\hline 6 & -0.54 & $0^{(a)}$ \\
\hline 7 & -0.51 & $0^{(a)}$ \\
\hline
\end{tabular}

(a) Regression coefficients are not significantly different from zero at the $10 \%$ level.

TABLE 7.3. Estimated Impact of a 20\% Increase in She11 Thermal Efficiency on Air Conditioning Energy Demand

\begin{tabular}{|c|c|c|}
\hline $\begin{array}{l}\text { Weather } \\
\text { Zone }\end{array}$ & $\begin{array}{l}\text { Upper Bound } \\
\text { Estimate } \\
\text { (Using Price } \\
\text { Elasticity) } \\
\end{array}$ & $\begin{array}{r}\text { Lower Bou } \\
\text { Estimate } \\
\text { Efficienc } \\
\text { Elasticit } \\
\end{array}$ \\
\hline 1 & $-18.4 \%$ & $-11.6 \%$ \\
\hline 2 & $-18.6 \%$ & $-7 \%$ \\
\hline 3 & $-17 \%$ & $-5.4 \%$ \\
\hline 4 & $-14.2 \%$ & $0 \%$ \\
\hline 6 & $-9.2 \%$ & $0 \%$ \\
\hline 7 & $-9.8 \%$ & $0 \%$ \\
\hline
\end{tabular}


implies that a 20 percent increase in efficiency (as a result of BEPS, other government programs or fuel price changes) will cause a 9.2 percent decrease in residential energy consumption. (a) The efficiency el asticity estimate implies that a 20 percent increase in efficiency will cause no decrease in residential energy consumption (the regression coefficient is not significantly different from zero therefore the impact is estimated to be zero). Upper and lower bound estimates of the impact of a 20 percent increase in shell efficiency on residential energy demand are provided in Table 7.3. (b) Given the weaknesses of the method used to construct the efficiency index, the authors hypothesize that the upper bound estimates are closer to the actual impact that the estimates derived from the efficiency elasticities.

\subsubsection{Natural Gas Heat}

A similar approach to that used to estimate the summer electric consumption equation was used to estimate a winter gas consumption equation (winter is defined as including the months of November, December, January, and February). The specification selected has the same advantages. It produces short run price elasticity estimates by climate zone and heating degree day levels within a climate zone, and efficiency elasticity estimates-by climate zone.

The following equation was estimated for households using natural gas as their primary heating fuel.

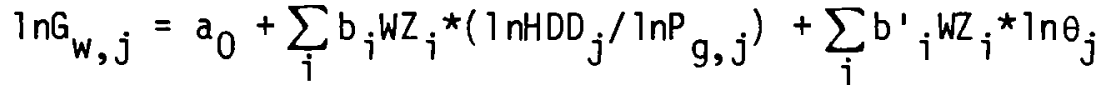

$$
\begin{aligned}
& +b_{9} \ln Y_{j}+b_{10} \operatorname{lnRM_{j}}+b_{11} \operatorname{lnP} g_{g, j} \operatorname{lnGAX_{j}}+e \\
& (i=1,2,3,4,7) \\
& \left(j=1, \ldots, n^{\prime}\right)
\end{aligned}
$$

where

$$
\begin{aligned}
G_{w, j}= & \text { average winter electricity consumption per day for household } \\
& j \text { (November, December, January, February 1978) }
\end{aligned}
$$

(a) Figure 1 shows the location of the seven AIA climate zones.

(b) Twenty (20) percent is used here strictly for illustrative purposes. The ratio of estimated savings to improved thermal efficiency is constant by assumption. Thus, a 15 percent improvement in thermal efficiency would cause the percent energy savings estimate to decrease by one quarter relative to the 20 percent savings estimate. 


$$
\begin{aligned}
H D D_{j}= & \text { average heating degree days per day for household } j \\
& \text { (November, December, January, February 1978) } \\
P_{g, j}= & \text { the average of the (consumer) marginal prices for gas in } \\
& \text { household } j \text { for November, December, January, February } 1979 \\
G A X_{j}= & \text { gas appliance index that equals average cu. ft. usage for all } \\
& \text { non-space conditioning appliances in household } j \text { (see Section } 6 \\
& \text { for a complete description of this variable). }
\end{aligned}
$$

Empirical results for Equation 7.2 are presented in Table 7.4. A small number of households in the data set residing in climate zone 6 used gas to heat, thus, cl imate zone 6 interactions were excluded from the equation (observations from $\mathrm{cl}$ imate zone 6 were deleted from the regression). The income elasticity estimate and the number of rooms elasticity estimates are 0.06 and 0.60 respectively.

The space conditioning fuel price elasticity and efficiency elasticity est imates for natural gas heating are provided in Table 7.5. Although the pattern is not quite as obvious as before, the estimates show the same inverse relationship between elasticities as was observed in the summer electricity demand equation. The natural gas heating price elasticity estimates for the northern $\mathrm{cl}$ imates are less than (in an absolute sense) the air conditioning price elasticity estimates for the southern climates. This result is not suprising given that households in northern $c l$ imates spend a greater percentage of their budget to heat than do households in the southern $\mathrm{climates}$ to air condition.

Table 7.6 shows the upper and lower bound estimated impact of a 20 percent increase in shell thermal efficiency on gas consumption. (a) Due to the method used to generate the efficiency index the authors again hypothesize that the estimates derived from the price elasticity are closer to the actual impact than the estimates derived from the efficiency el asticity.

(a) Twenty (20) percent is used here strictly for illustrative purposes. The ratio of estimated savings to improved thermal efficiency is constant by assumption. Thus, a 15 percent improvement in thermal efficiency would cause the percent energy savings estimate to decrease by one quarter relative to the 20 percent savings estimate. 
TABLE 7.4. Gas Heating Empirical Results

\begin{tabular}{|c|c|c|}
\hline Variable & $\begin{array}{l}\text { Regression } \\
\text { Coefficient (b) } \\
\end{array}$ & $\begin{array}{l}\text { Standard } \\
\text { Error of b }\end{array}$ \\
\hline Intercept & $-1.281^{(a)}$ & 0.191 \\
\hline$W Z_{1} *\left(\operatorname{lnCDO}{ }_{j} / \operatorname{lnP} g_{j i}\right)$ & $1.341^{(a)}$ & 0.110 \\
\hline$W Z 2^{*}\left(\operatorname{lnCDD}{ }_{j} / \operatorname{lnP} g_{j i}\right)$ & $1.356^{(a)}$ & 0.103 \\
\hline $\mathrm{WZ}_{3}{ }^{\star}\left(\operatorname{lnCDO}{ }_{j} / \operatorname{lnP}_{g_{i j}}\right)$ & $1.392^{(a)}$ & 0.107 \\
\hline$W_{4}{ }^{*}\left(\operatorname{lnCDD}{ }_{j} / \operatorname{lnP}_{g_{j j}}\right)$ & $1.235^{(a)}$ & 0.141 \\
\hline $\mathrm{WZ}_{7}{ }^{\star}\left(\operatorname{lnCDD} \mathrm{C}_{j} / \operatorname{lnP}_{g_{i j}}\right)$ & $1.208^{(a)}$ & 0.130 \\
\hline$W Z_{1}{ }^{\star} \ln \theta_{j}$ & $-0.250^{(a)}$ & 0.072 \\
\hline$W Z_{2}{ }^{\star} \ln \theta_{j}$ & $-0.122^{(b)}$ & 0.053 \\
\hline$W Z_{3}{ }^{*} \ln \theta_{j}$ & $-0.374^{(a)}$ & 0.052 \\
\hline$W Z_{4}{ }^{*} \ln \theta_{j}$ & $-0.156^{(a)}$ & 0.061 \\
\hline$W Z_{7}{ }^{\star} \ln \theta_{j}$ & -0.302 & 0.212 \\
\hline $\ln \gamma_{j}$ & $0.055^{(a)}$ & 0.016 \\
\hline $\operatorname{lnRM} M_{j}$ & $0.619^{(a)}$ & 0.051 \\
\hline $\operatorname{lnP}_{g_{i j}} \ln G X_{j}$ & $0.004^{(a)}$ & 0.001 \\
\hline \multicolumn{3}{|l|}{$R^{2}=0.385$} \\
\hline$F=70.09$ & & \\
\hline Observations $=1,470$ & & \\
\hline
\end{tabular}

(a) Significant at $1 \%$ level.

(b) Significant at 5\% level. 
TABLE 7.5. Gas Heat Price and Efficiency Elasticity Esimates

\begin{tabular}{|c|c|c|}
\hline $\begin{array}{l}\text { Weather } \\
\text { Zone }\end{array}$ & $\begin{array}{c}\text { Price } \\
\text { Elasticity } \\
\end{array}$ & $\begin{array}{l}\text { Efficiency } \\
\text { Elasticity }\end{array}$ \\
\hline 1 & -0.46 & -0.25 \\
\hline 2 & -0.46 & -0.12 \\
\hline 3 & -0.45 & -0.37 \\
\hline 4 & -0.32 & 0.16 \\
\hline 7 & -0.35 & $0^{(a)}$ \\
\hline
\end{tabular}
(a) Regression coefficient is not signifi- cantly different from zero at the $10 \%$ level.

TABLE 7.6. Estimated Impact of a $20 \%$ Increase in She 11 Thermal Efficiency on Gas Heat Energy Demand

\begin{tabular}{|c|c|c|}
\hline $\begin{array}{l}\text { Weather } \\
\text { Zone }\end{array}$ & $\begin{array}{l}\text { Upper Bound } \\
\text { Estimate } \\
\text { (Using Price } \\
\text { Elasticity) }\end{array}$ & $\begin{array}{l}\text { Lower Bound } \\
\text { Estimate } \\
\text { Efficiency } \\
\text { Elasticity } \\
\end{array}$ \\
\hline 1 & $-10.8 \%$ & $-5 \%$ \\
\hline 2 & $-10.8 \%$ & $-2.4 \%$ \\
\hline 3 & $-11 \%$ & $-7.4 \%$ \\
\hline 4 & $-13.6 \%$ & $-3.2 \%$ \\
\hline 7 & $-13 \%$ & $0 \%$ \\
\hline
\end{tabular}




\subsubsection{Electric Heat}

The same type of specification used to estimate the summer electric equation and the winter gas consumption equation could not be used to estimate the winter electric consumption equation. First, the price, appliance index interaction terms could not be used to separate the space conditioning appliance, price relationship from the non-space conditioning appliance price relationship. If a household used electricity to heat then in almost all cases the household used electricity for all other household appliances. Thus, the appliance index among electrically heated houses had very little variation. As a result the price, appliance index interaction term picked up the entire price, consumption effect as opposed to just the relationship between non-space conditioning appliances and price.

Second, a relatively small percentage of the households within the data set heated with electricity (approximately 375 households). In addition, most of the electric heated houses were in the South. As a result, the sample size of electric heated houses for many $\mathrm{climate}$ zones was extremely small. The specification used to estimate the summer electric and winter gas consumption equations required a large number of observations in each $\mathrm{climate} z$ one. Use of a small number of observations (such as the number of electric heated households in several climate zones in the data set) could lead to relatively unstable price and efficiency el asticity estimates.

After attempting several specifications the standard Appliance Disaggregrate approach was selected (see Section 4.0 for a complete discussion of this approach). This approach uses observations with households that use electricity to heat as well as observations with households that do not use electricity to heat. Thus, sample size is not a problem. Second, this approach produces space conditioning price and efficiency el asticities (although not by $\mathrm{climate}$ zone as with the previous specifications). Third, this approach produces a short run price el asticity estimate by incorporating information on the stock of appliances in the household in the demand equation.

The following winter electricity demand equation was estimated for all observations in the data set. 


$$
\begin{aligned}
& \operatorname{lnE} w_{, j}=a_{0}+b_{1} D H_{j}+b_{2} D C_{j}+b_{3} D D w_{j}+b_{4} D C D_{j} \\
& +b_{5} \mathrm{DFF}_{j}+\mathrm{b}_{6} \mathrm{DH}_{j} \star \mathrm{RM} \mathrm{j}_{j}+\mathrm{b}_{7} \mathrm{DH}_{j} \star \mathrm{RM}_{j} \star Y_{j} \\
& +b_{8} D H_{j} \star R M_{j} \star P e_{j}+b_{9} D H_{j} * R M_{j}{ }_{j} \\
& +b_{10} D_{j} H_{j} R M_{j} \star H D D_{j}+b_{11} P_{e, j} E^{*} E_{j}+e
\end{aligned}
$$

where

$$
\begin{aligned}
\mathrm{E}_{\mathrm{w}, \mathrm{j}}= & \text { average winter electricity consumption per day in household } j \\
& \text { (November, December, January, February } 1977-1978) \\
\mathrm{DH}_{j}= & \text { dummy var } \mathrm{iable} \text { for electric heat (DH=1 if electricity is used } \\
& \text { to heat and } \mathrm{DH}=0 \text { otherwise) in household } j \\
\mathrm{DC}_{j}= & \text { dummy variable for presense of electric range and oven in } \\
& \text { household } j \\
\mathrm{DDW}_{\mathrm{j}}= & \text { dummy variable for presense of dishwasher in household } j \\
\mathrm{DCD}_{j}= & \text { dummy variable for presense of electric clothes dryer in } \\
& \text { household } j \\
\mathrm{DFF}_{j}= & \text { dummy variable for presense of food freezer in household } j .
\end{aligned}
$$

As was noted above, this specification produces a space conditioning price elasticity estimate and a efficiency elasticity estimate. The space conditioning price elasticity estimate can be derived from the regression coefficient on the heating durmy, number of rooms, price interaction term. The thermal efficiency el asticity estimate can be derived from the regression coefficient on the heating dumy, number of rooms, efficiency index interaction term. Inclusion of the electric heat dummy variable in the interaction terms causes the interaction term to equal zero unless the household uses electricity to heat. In this way the price and efficiency elasticity estimates are derived for only electrically heated houses (see Section 4 for more details on the relative strenghts and weaknesses of this type of approach).

The interaction between price and non-space conditioning appliances is purged from this estimate due to the inclusion of the price, electric appliance index interaction term. This is the same type of approach that was used for the summer electric consumption and the winter gas consumption equations. 
The empirical results for Equation 7.3 are presented in Table 7.7. The space conditioning price elasticity estimate is -0.32 and the efficiency elasticity estimate is -0.34 . (a) These elasticities are national average est imates only.

These elasticity estimates provide an upper and lower conservation impact estimate. Using the price elasticity, a 20 percent increase in shell thermal efficiency would cause a 13.6 percent decrease in winter electricity consumption. Using the efficiency estimate, a 20 percent increase in shell thermal efficiency would cause a 6.8 percent decrease in winter electricity consumption. As in the air conditioning and gas heating cases, the authors hypothesize that the conservation impact estimate derived from the price elasticity is closer to the true value than the estimate derived from the efficiency elasticity.

\subsubsection{Limitations of the Energy Demand Resu 1 ts}

The residential energy demand empirical results have been used to estimate the impact of conservation on residential demand; however, two careats should be added to these conclusions. First, the empirical analyses imposed a specific relationship between efficiency levels and energy consumption as well as between price and energy consumption (e.g., a log-log relationship). The specifications may not describe the actual relationships. However, tests of alternative functional forms proved less satisfactory than the specifications described above. Second, the conservation impact estimates are only valid within the

(a) The price elasticity was calculated with the following formula:

$$
E L^{P}=\left(b_{8} \overline{R M}_{e h}\right)\left(\bar{P}_{e, e h} \bar{E}_{w, e h}\right)
$$

where $\quad E L^{p}=$ electric heating fuel price elasticity of demand

$$
\begin{aligned}
\overline{\mathrm{RM}}_{\mathrm{P}} & =\text { mean } \mathrm{RM} \text { for electrically heated houses } \\
\frac{\mathrm{P}}{\mathrm{E}} \text {, eh } & =\text { mean } \mathrm{P} \text { for electrically heated houses } \\
\mathrm{W}, \text { eh } & =\text { mean } E_{W} \text { for electrically heated houses }
\end{aligned}
$$

The efficiency elasticity was calculated with the following forumula:

$$
E L_{e}=\left(b_{g} \overline{R M}_{e, h}\right)\left(\bar{\theta}_{e h} / \bar{E}_{w, e h}\right)
$$

where $\quad E L_{e}=$ theraml efficiency energy demand eesticity

$\bar{\theta}_{\text {eh }}=$ mean $\theta$ for electrically heated houses 
TABLE 7.7. Electric Heat Empirical Results

\begin{tabular}{|c|c|c|}
\hline Variable & $\begin{aligned} & \text { Regression } \\
& \text { Coefficient (b) } \\
&\end{aligned}$ & $\begin{array}{l}\text { Standard } \\
\text { Error of b }\end{array}$ \\
\hline Intercept & $6.99^{(a)}$ & 1.02 \\
\hline $\mathrm{DH}_{\mathrm{j}}$ & $28.85^{(a)}$ & 3.21 \\
\hline $\mathrm{DHW}_{\mathrm{j}}$ & $5.28^{(a)}$ & 0.69 \\
\hline $\mathrm{DHD}_{j}$ & $5.12^{(a)}$ & 0.71 \\
\hline $\mathrm{DFF}_{j}$ & $3.49^{(a)}$ & 0.66 \\
\hline $\mathrm{DH}_{j}{ }_{j} \mathrm{RM}_{j}$ & $4.02^{(a)}$ & 0.90 \\
\hline $\mathrm{DH}_{j}{ }^{\star R M_{j}}{ }^{\star}{ }_{j}$ & $0.00006^{(a)}$ & 0.000009 \\
\hline$D H_{j} \star R M_{j} \star P e_{j}$ & $-1.65^{(a)}$ & 0.15 \\
\hline $\mathrm{DH}_{j} \star \mathrm{RM}_{j} \star \mathrm{O}_{j}$ & $-2.96^{(a)}$ & 0.24 \\
\hline $\mathrm{DH}_{j} \star R M_{j} \star H D D_{j}$ & $0.419^{(a)}$ & 0.02 \\
\hline$P_{e}{ }^{\star E X X} X_{j}$ & $0.00002^{(a)}$ & 0.212 \\
\hline \multicolumn{3}{|l|}{$R^{2}=0.721$} \\
\hline \multicolumn{3}{|l|}{$F=684.27$} \\
\hline Observations $=2,930$ & & \\
\hline
\end{tabular}

(a) Significant at $1 \%$ level. 
range of changes in the price and efficiency variables. Marginal price ranges from below one to greater than ten cents a kWh with a mean of 3.98. The efficiency index ranges from 0.48 to above 5 with a mean of 1.32 .

\subsection{ENERGY USAGE "TECHNOLOGY"}

In the long run, the stock of energy using appliances is not fixed as is assumed in the preceeding analysis, rather households adjust their holdings to some optimal level given relative prices and their income. The long run decisions related to residential energy usage faced by consumers include the type of heating fuel, the thermal efficiency of their residence, and air conditioning equipment. The air conditioning decision can be separated into two sequential decisions: 1) Whether to acquire any air conditioning equipment, and 2) If so whether to have central air conditioning or window type units. Results for the four equations are discussed below.

\subsubsection{Primary Heating Fuel}

One of the most basic choices made by households relating to energy consumption is the type of primary heating fuel used in the home. This choice will significantly influence the characteristics of the heating system and the optimal level of thermal efficiency. Thus, the fuel choice and efficiency equations form a recursive system (i.e., first the fuel choice decision is made and then the efficiency of the structure is determined).

As is discussed in the methodology section, the principal determinant of the type of fuel used to heat is the relative price of alternative fuels. For this analysis only natural gas and electricity are considered, mainly due to the 1 ack of adequate price data for other fuel types. The other principal determinant of fuel choice is the climate of the local area. The more intensively the heating system is utilized the more important operating costs become relative to capital equipment costs. Thus, one would expect less reliance on electric heat in colder climates because of the relatively low capital costs associated with electric heat. Other independent variables in the regression equation include the structure's age (a dummy variable if the structure was built before 1960), a dummy variable for owner occupied units and a dumy variable for single family dwellings. 
The last variable included in the regression was a dumy variable for areas where no household in the DOE sample location heated with natural gas. For the locations where natural gas was not in use a price could not be determined. In these situation the natural gas price was set to zero and the durmy variable (NOGAS) was set equal to one. Without this procedure many oberservation would be lost because of missing values. The coefficient on the durmy variable (NOGAS) will equal the product of the mean price of natural gas in those areas and the regression coefficient for price of natural gas.

$$
\begin{aligned}
\ln \left(F_{g} / F_{g}\right)= & b_{0}+b_{1} P_{e}+b_{2} P_{g}+b_{3} H D D+b_{4} O W N+b_{5} P D \\
& +b S F+b \text { NOGAS }+u
\end{aligned}
$$

The results of the fuel choice regression are shown below in Table 7.8. The dependent variable ( $F G$ ) is a dichotomous variable equal to one if natural gas is used as the primary heating fuel and equal to zero if electricity is used as the primary heating fuel. The coefficient on each variable is statistically significant and has the expected direction of impact on the probability of heating with natural gas. The one exception to this is coefficient on OWN which was negative and significant. The negative coefficient would indicate that electric heating tends to be a custom feature in a residence that is desired by a 1 imited subsegment of the consumers.

The price of electricity has a positive sign and the price of natural gas has a negative sign, as would be expected, since they are substitute commodities. The size of the coeficient on $\mathrm{P}_{g}$ indicates that the choice of natural gas as the primary heating fuel is relatively insensitive to the natural gas price. Evaluated at the group probablity of heating with natural gas (0.8), a ten percent increase in price would decrease the probability of natural gas use by 0.0179 . On the other hand, the choice of natural gas as the primary heating fuel is more sensitive to the price of electricity. A ten percent increase in electricity prices would decrease the probability of heating with electricity by 0.0733 . This difference in price responsiveness to the prices of the two fuels could be the result of federal regulation of the price of natural gas, such prevailing natural gas prices are poor measures of the expected price faced by the consumer. 
Heating requirements as measured by typical annual heating degree days (HDD) is a significant determinant of fuel choice. For example, evaluated at the group probability of heating with natural gas (0.8) a household in an area which is ten percent colder than the average location would have a 0.039 higher probability of heating with natural gas holding all other factors constant.

There are a few qualifications which must be noted regarding the fuel choice analysis. The NIECS data set, although a rich cross-sectional survey, is not especially suited for this type of analysis. The sample design which generates a representative national cross-section introduces rather homogeneous local area observations, as all households in sample location are drawn from the same neighborhood. If the sample was more dispersed in the local area then we would expect to observe more variation in fuel use for each set of relative fuel prices. This problem is further aggrevated by our inability to identify the respondent's location so that a full complement of fuel prices can be observed. Finally, it would to preferable to simultaneously estimate the fuel choice for all major fuels (natural gas, fuel oil, liquified propane gas and electricity). Not only would this be more comprehensive, but more efficient statistical estimates could be obtained in that probabilities of each fuel type would be more equal. When the proportion of households using natural gas is so high as it was in this sub-sample, the response to any one independent variable is implicitly limited.

\subsubsection{The Level of Thermal Efficiency}

It is assumed that the next deision the residential energy consumer makes is on the level of thermal efficiency of his home. The optimal level of efficiency is determined by the costs and benefits of increasing thermal efficiency. Factors which affect this level include the price of the primary heating fuel (electricity or natural gas), the type of fuel, heating requirements, the type of structure and the cost of building more efficient structures. Unfortunately, because the location of the observations are not known, it is impossible to link the appropriate building cost indices. Thus, we must proceed under the assumption that there not significant cross-sectional differences in the supplies of such items as insulation and storm doors and windows. Therefore, the cost of building is omitted as an explanatory variable. 
TABLE 7.8. Fuel Choice LOGIT Regression Results - Gas Heat Independent

Variables

Intercept

$\mathrm{P}_{\mathrm{e}}$

$P_{g}$

HDD

OWN

PD1

SF

NOGAS

\section{Coefficient}

$-2.2928^{(a)}$

$1.1612^{(\mathrm{a})}$

$-0.0593^{(b)}$

$0.0005^{(a)}$

$-1.0864^{(a)}$

$1.9039^{(a)}$

$1.1264^{(a)}$

$-6.5487^{(a)}$
Standard Error

0.888

0.113

0.025

0.0001

0.298

0.246

0.291

0.706

Observations $=1,875$

(a) Significant at the $1 \%$ level.

(b) Significant at the $5 \%$ level.

TABLE 7.9. Thermal Efficiency Level Regression Results

\begin{tabular}{lccc} 
Variable & & Coefficient & Standard Error \\
\cline { 2 - 3 } Intercept & 0.542 & 0.336 \\
ln $\mathrm{Pe}_{\mathrm{e}}$ & $0.281^{(\mathrm{a})}$ & 0.078 \\
ln $\mathrm{P}_{\mathrm{g}}$ & $0.204^{(\mathrm{a})}$ & 0.061 \\
In HDD & $0.194^{(\mathrm{a})}$ & 0.031 \\
In Y & 0.031 & 0.021 \\
$\mathrm{AGE}$ & $0.004^{(\mathrm{a})}$ & 0.001 \\
$\mathrm{~F}_{\mathrm{g}}$ & $-0.403^{(\mathrm{b})}$ & 0.209 \\
$\mathrm{SF}$ & $-1.784^{(\mathrm{a})}$ & 0.046 \\
$\mathrm{R}^{2}=0.559$ & & \\
Observations $=1,458$ &
\end{tabular}

(a) Significant at the $1 \%$ leve 1 .

(b) Significant at the $10 \%$ level. 


$$
\begin{aligned}
= & b_{0}+b_{1} \ln P_{e}+b_{2} \ln P_{g}+b_{3} \ln A D D+b_{4} \ln V \\
& +b_{5} A G E+b_{6} F_{g}+b_{7} S F+e
\end{aligned}
$$

Two other independent variables entering the regression are the age of the structure and household income. The structure's age is included to capture any cohort effects which result in different optimal efficiency levels for residences built in different periods. The household income variable is included to test primarily for capital market effects. It is generally accepted that as a household's income increases their cost of borrowing tends to decrease. If this is the case then the optimal efficiency level for high income households will be greater than for low income households. Thus the coefficient on the income variable is excepted to be positive. The results for this regression equation are shown below in Table 7.9.

The fuel price elasticities for thermal efficiency are positive, as expected, with the electricity price elasticity being slightly higher than the natural gas price elasticity. In most cases, the cost per Btu is higher for electricity which would suggest that those heating with electricity are on a more elastic portion of their demand function for efficiency. The fuel price elasticities are rather low $(0.204-0.281)$. For natural gas users, a one percent increase in the price of natural gas would result in a 0.2 percent increase in thermal efficiency. For those heating with electricity, a one percent increase in electricity price will result in a 0.28 percent increase in thermal efficiency.

If households have not fully adjusted their efficiency level to the equilibrium position indicated by the recent esculation in energy prices then these estimated coefficients are bias downward. Given the estimated coefficients on price it would take doubling of residential energy prices to induce the level of efficiency suggested by BEPS. There is another downward bias in the estimate in that sample is dominated by existing homes where increasing efficiency may be more difficult and thus less responsive to fuel prices than new construction.

The coefficient on heating degree days is positive and statistically significant. A one percent increase in the heating degree days will induce 
households to increase their thermal efficiency level by 0.2 percent. The coefficient on household income is positive as indicated by the capital market hypothesis, however it is not significantly different from zero at a high confidence level. The regression results also show that homes heating with natural gas are less efficient than electrically heated homes and that single family detach residences are not as effecient as multiple units. This last results is simple an engineering phenomenon in that multiple unit structures have proportionately less external surface area per square foot of living than do single family detached homes.

The last variable in the regression is the age of the structure. Intuitively, one would expect that newer residences to be more thermally efficient than older residences. The regression results do not confirm such a relationship. The estimated coefficient on the age-of-the-structure is a positive 0.004 and is significantly different from zero at the 99 percent level. This would indicate that on average one older home would increase be 0.4 percent more efficient by our index. This, of course, cannot take into account difficult to quantify factors such as the actual air infiltration rate.

There are several factors which could account for the results on the ageof-the-structure variable including statistically characteristics of the data which may not have been considered. Beyond that two technical explanation are possible. First, the real price of energy has been declining until fairly recently. Thus, older homes contained more energy efficient characteristics than newer homes and only recently has the price of energy increased the incentive to build more efficient homes. Another economic explanation is that augmenting the efficiency characteristics of the structure can easily be a "home production" activity such that the older the residence the more efficiency characteristics are added to the residence. This would depend on two factors. One, the acquisition of specific information on the structure which is obtained by living the residence. Two, production being labor intensive but not requiring highly specialized skills.

\subsubsection{Choice of Air Conditioning Equipment}

The decision to acquire air conditioning equipment can conveniently be considered as two sequential decisions. The first question is whether to have 
any air conditioning equipment at all, and the second question is whether to have a central unit or window units. Thus, to examine the factors that affect these decisions, we estimate two separate equations. As was done for the fuel choice equation which involves a dichotomous dependent variable, a LOGIT regression technique is employed for both air conditioning and central air conditioning equations.

Each equation is specified with the same explanatory variables: the price of electricity during the cooling months $\left(P_{e}\right)$, household income $(Y)$, annual average cooling degree days (CDD), the age of the residential structure (AGE), and dummy variables for owner occupied houses (OWN), for mobile homes (MH), for rural area residences (RURAL), and for observations in AIA climate zone 3 and outside the western states $(\mathrm{CZW} 3)$. The choice of the form of the variables entering the LOGIT function, logarithmic versus arithmetic forms, is somewhat arbitrary. However, results for the logarithmic forms of the continuous independent variables are reported below. The chief advantage of this approach is that it increases the symmetry of the independent variables' distributions. This, in turn, appears to improve the statistical properties of the regression. The regression results for the presence of air conditioning equipment in a household are presented in Table 7.10.

$$
\begin{aligned}
(A C / 1-A C)= & b_{0}+b_{1} \ln P_{e}+b_{2} \ln Y+b_{3} \ln C D D+b_{4} \ln A G E \\
& +b_{5} \text { OWN }+b_{6} \text { RURAL }+b_{7} M H+b_{8} C W Z 3+e
\end{aligned}
$$

The independent variables have the expected signs and are statistically significant. The one exception to this is the dumy variable for mobile homes (MH) which is negative as expected but not significantly different form zero. The price of electricity has significant negative affect on the probability of have any type of air conditioning equipment. The coefficient on $\ln \left(\mathrm{P}_{e}\right)$ implies that a one percent increase in the price of electricity will reduce the odds of have air conditioning 0.425 percent. For the typical household, an increase of one cent per kilowatt-hour will decrease the probability of having air conditioning by 0.023 . Household income is highly significant, and as is expected, high income households have higher probabilities of having air conditioning. Cooling degree days, In (CDD), is a highly significant 
TABLE 7.10. Air Conditioning LOGIT Regression Results

\begin{tabular}{|c|c|c|}
\hline $\begin{array}{c}\text { Independent } \\
\text { Variables }\end{array}$ & Coeffic ient & Standard Error \\
\hline Intercept & $-14.53^{(a)}$ & 0.868 \\
\hline $\ln \left(P_{e}\right)$ & $-0.425^{(a)}$ & 0.123 \\
\hline $\ln (Y)^{\prime}$ & $0.699^{(a)}$ & 0.061 \\
\hline $\ln (\operatorname{CDD})$ & $1.403^{(a)}$ & 0.068 \\
\hline $\ln (A G E)$ & $-0.274^{(a)}$ & 0.056 \\
\hline OWN & $0.303^{(a)}$ & 0.116 \\
\hline RURAL & $-0.560^{(a)}$ & 0.100 \\
\hline MH & -0.158 & 0.192 \\
\hline CWZ3 & $0.615^{(a)}$ & 0.107 \\
\hline
\end{tabular}

Observations $=2,923$

(a) Significant at the $1 \% 1$ evel.

TABLE 7.11. Central Air Conditioning LOGIT Regression Results

\begin{tabular}{|c|c|c|}
\hline Variable & Coefficient & Standard Error \\
\hline Intercept & -6.339 & $29.98^{(a)}$ \\
\hline $\ln \left(P_{0}\right)$ & -0.194 & 1.23 \\
\hline $\ln (Y)$ & 0.638 & $57.63^{(a)}$ \\
\hline $\ln (C D D)$ & 0.488 & $29.39^{(a)}$ \\
\hline In (AGE) & -1.255 & $223.87^{(a)}$ \\
\hline OWN & -0.447 & $7.34^{(a)}$ \\
\hline RURAL & -0.479 & $12.93^{(a)}$ \\
\hline MH & -0.688 & $8.59^{(a)}$ \\
\hline CWZ3 & 0.310 & $5.56^{(b)}$ \\
\hline
\end{tabular}

Observations $=1,748$

(a) Significant at the $1 \%$ level.

(b) Significant at the $5 \%$ level. 
determinant of the having air conditioning equipment. Its coefficient indicates that a one percent increase on cooling degree days increases the odds of having air conditioning by 1.4 percent.

The results also indicate that older residential units are less likely to have air conditioning equipment than are new homes. There are two factors which support this finding. Since the equipment was not as readily available when many older homes were built they were designed to reduce cooling requirements. Second, retrofitting costs for some types of air conditioning equipment would be substantially greater than installation in new homes. The regional/climate zone dummy variable (CWZ3) appears to capture the interaction between temperature and hummidity. Even after controlling for cooling degree days CWZ3, which is based in part on the level of cooling degree days, has a significant positive impact on the probability of having air conditioning. The areas designated by this variable tend to have high hummidity levels.

The decision in the choice of air conditioning equipment is whether to have a central air conditioning unit. A LOGIT regression procedure is used to identify the factor which affect the probability of having central air conditioning. For this analysis, only those households which have some type of air conditioning equipment are included. The explanatory variables are the same as those entering the air conditioning equipment (any type) discussed above. The results for central air conditioning are shown in Table 7.11.

$$
\begin{aligned}
(C A C / 1-C A C)= & b_{0}+b_{1} \ln P_{e}+b_{2} \ln Y+b_{3} l n C D D+b_{4} l n \text { AGE } \\
& +b_{5} \text { OWN }+b_{6} \text { RURAL }+b_{7} M H+b_{8} C W Z 3+u
\end{aligned}
$$

A11 independent variables, except the price of electricity $\left(P_{e}\right)$, are significantly different from zero. The electricity price does enter the regression with the expected negative sign. The primary determinants having central air conditioning given the household has some type of air conditioning equipment are $Y$ and $C D D$. As in the case having any type of air conditioning equipment, areas which have high hummidity and a large number of cooling degree days, designated by CWZ3 are more likely to have central air conditioning. Owner occupied residences also are more likely to have a central air conditioning unit. 
In the choice of central air conditioning, AGE is capturing the higher retrofitting cost for older residences, as indicated by its highly significant negative coefficient. Other factors which reduce the likelihoold of having central air conditioning are living in a rural area (RURAL) and living in a mobile home (MH). 


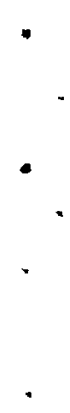




\section{REFERENCES}

Chern, W. and W. Lin. 1978. "Energy Demand for Space Heating in the United States." Econometric Studies in Energy Demand and Supply. Edited by G. Maddala et a 1., New York, Praeger Publishers.

Christensen, L. et al. June 1975. "Transcendental Logarithmic Utility Functions." American Economic Review 65:367-83.

Christensen, L. and M. Maser. 1975. "Cost-of-Living Indexes and Price Indexes for U.S. Meat and Produce." Household Production and Consumption. Edited by N. Terleckyj, New York, Columbia University Press.

Deaton, A. and J. Muellbauer. June 1980. "An Almost I deal Demand System." American Economic Review 70:312-26.

Glandon, G. and H. Pollakowski. 1978. "The Residential Demand for Energy." Presented at the Econometric Society Meetings, Chicago I11., Aug. 29-31, 1978.

Hausman, J. et a1. 1979. "A Two Level Electricity Demand Model." Journal of Econometrics 10:263-89.

Houthakker, H. April 1960. "Additive Preferences." Econometrica 28:244-57.

Houthakker, H. et al. May 1974. "Dynamic Demand Analyses for Gasoline and Residential Electricity." Journal of Agricultural Economics $56: 412-418$.

Miedema, et a1. 1978. "Time-0f-Use Price Effects - Arizona." Research Triangle Institute, Research Triangle Park, N.C.

Muellbauer, J. December 1974. "Household Production Theory, Quality, and the Hedonic Technique." Americ an Economic Review 64:977-94.

Parhizgari, A. and P. Davis. 1978. "The Residential Demand for Electricity: A Variant Parameters Approach." Applied Economics 10:331-40.

Parti, M. and C. Parti. Spring 1980. "The Total and Appliance Specific Conditional Demand for Electricity in the Household Sector." Bell Journal of Economics $11: 309-21$.

Pindyck, R. 1978. "International Comparisons of the Residential Demand for Energy." European Economic Review 13:1-24.

Stone, J. Sept. 1954. "Linear Expenditure Systems and Demand Analysis: An Application to the Pattern of British Demand." Economic Journal 64:511-27.

Taylor, L. et al. January 1977. "Residential Demand for Energy." Final report, Vol. I, Electric Power Research Institute. 
U.S. Department of Energy (DOE). 1979. Economic Analys is of Energy Performance Standards for New Buildings. Office of Conservation and Solar Applications, Washington, D.C.

Warren-Boulten, F. R. June 1978. "The Effect of Factor-Augmenting Technical Change on Factor Demand, and the Response by Factor Supplies." Presented to the Western Economics Association, Honolulu, Hawai i.

Werth, A. June 1978. "Residential Demand for Electricity and Gas in the Short Run: An Econometric Analys is." MIT Energy Laboratory Working Paper.

Wold, H. 1953. Demand Analysis: A Study in Econometrics. New York, 1953. 


\section{APPENDIX A}

The thermal efficiency index for single family and multi-family housing was obtained through the use of the DOE-2 Building Thermal Analysis Program. This program is capable of calculating an estimate of the energy consumption of a building's heating and cooling systems by simulating the hour by hour performance of that building. DOE-2 and the Building Design Language (BDL) that accompanies it were developed for architects and engineers as an aid to designing energy efficient buildings. The Building Design Language is capable of detailed descriptions of a building's construction and, with the weather data available, can calculate the hourly, daily, monthly, and the annual energy used to heat and cool a building in a specific climate.

DOE-2 is capable of performing parametric runs that al low comparison of variations in energy use resulting from changes in the building's construction. It is this aspect of the program that led us to choose it as a method for estimating the energy used to heat and cool a single family home for the period of one year. It was possible to "construct" 250 unique homes by combining the data available in the NIECS data set with some assumptions to cover for information not available in the data set. Many aspects of each house remained the same across all homes. These were incorporated into the DOE2 program itself. Aspects that changed from house to house (number and type of doors and windows, ceiling insulation, etc.) were parameterized at the beginning of the program.

In order to estimate the energy use data on the size, location, age, and fenestration of the house was needed. The NIECS data provided the following information.

- Number of square feet

- Number of windows and whether or not they were storm windows

- The year the house was built

- The amount of attic insulation and whether the walls were insulated

- Approximate location of the house

- The number of doors and whether or not they were storm doors

- The number of floors in the house. 
In order to run DOE-2 some information was required that was not available from the NIECS data. Several assumptions had to be made to eliminate these gaps.

The data set gave the number of floors per house as one, one and a half, two, etc. Only houses with whole number values for the number of floors were chosen and it was assumed that these were constructed as multiple floors of equal square footage. For example, a two-story home of 1600 square feet would be constructed as two floors of 800 square feet. The volume of the home was obtained by assuming eight foot interior ceilings and so multiplying the square footage by eight.

The missing values for the size of the exterior walls were calculated from available data in the following manner:

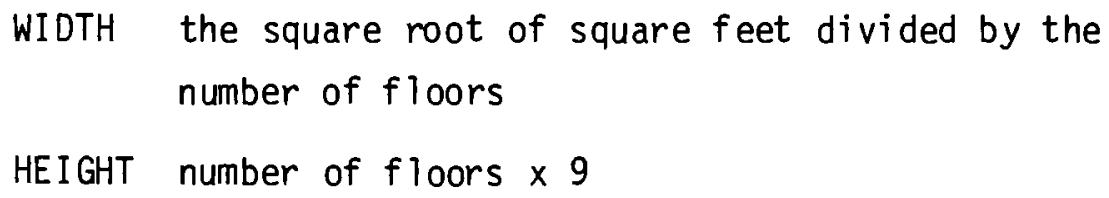

Lacking data on the shape of the house and the placement of the windows it was assumed that each house was square with four walls of equal size and that the windows were evenly distributed on all four sides. The NIECS data set differentiated windows as picture, sliding glass doors, casement, and other but not give dimensions for them. DOE-2 required the size of the windows so the following values were used throughout:

$$
\begin{aligned}
& \text { Picture windows } 5 \times 8 \text { feet } \\
& \text { Sliding glass door } 6.5 \times 8 \text { feet } \\
& \text { All other } 3 \times 4 \text { feet }
\end{aligned}
$$

The construction of the house for DOE-2 did not include a garage or a basement since this information was not included in the NIECS data set. It was assumed that no home had a basement and that all were constructed on a concrete slab. 


\section{$\underline{\text { DISTRIBUTION }}$}

No. of

Copies

OFFSITE

Mark Levine

Lawrence Berkeley Laboratory

1 Cyclotron Road

Berkeley, CA 94720

5 Peter Back

U. S. Department of Energy

Office of Alcohol Fuels

Forrestal Building, Rm. 6A-087

1000 Independence Ave., S.W.

Washington, D.C. 20585

Jean Rimpo

Bonneville Power Administration

Division of Power Requirements

2nd Floor, S.E.

847 N.E. 19th

Portland, OR 97208

Sam Bernstein

Gas Research Institute

8600 West Bryn Mawr Avenue

Chicago, IL 60631

Fred Abel

U.S. Department of Energy

Offices of Buildings Energy

Forrestal Building, Rm. 5G-063

1000 Independence Ave., S.W.

Washington, D.C. 20585

Eric Hirst

Oak Ridge National Laboratory

P.0. Box $X$

Oak Ridge, TN 37830

27 DOE Technical Information Center
No. of

Copies

ONSITE

DOE Richland Operations Office

H. E. Ransom

10 Pacific Northwest Laboratory

R. C. Adams (3)

Publishing Coordination (2)

Technical Information Files (5) 


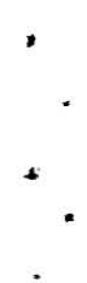

